\title{
An Exploratory Study into Entrepreneurial Motivation in Changing Contexts
}

By

Dylan Thom

\begin{abstract}
A thesis
Submitted to Victoria University of Wellington in partial fulfilment of the requirements for the degree of Master of Commerce in Management
\end{abstract}

Victoria University of Wellington 


\begin{abstract}
The purpose of this research is to explore entrepreneurial motivation and its relationship to change. It does this through providing insight into what entrepreneurial motivation is, and how it is affected by change. An interpretative phenomenological approach is taken in the exploration of the nature of entrepreneurial motivation and change, in order to understand the phenomena in terms of the lived experience of seven entrepreneurs from New Zealand. The key finding in this research was that entrepreneurial motivation is an internal drive that provides entrepreneurs with the energy to deal with obstacles and push forward in an effort to satisfy their need for achievement. Some insights into the nature of entrepreneurial motivation across changing contexts are provided. An improved understanding of what entrepreneurial motivation is and how it is affected by change provides implications for both practitioners and scholars. This provides value in terms of predicting individual propensity and viability of entrepreneurship.
\end{abstract}




\section{Acknowledgements}

This thesis was made possible thanks to many individuals and groups who helped me along my academic journey. Those entrepreneurs who gave me their time and stories of their own life experience provided me with the insight to conduct this thesis. I am extremely grateful for their openness and enthusiasm towards my research. I have learnt a lot not only about the subject matter but also about what it takes to be a successful entrepreneur in today's world. The mind-sets they divulged to me provided me with an understanding of what it will take to be successful in my professional and personal endeavours.

I am extremely grateful towards my supervisor at Victoria University Kala Retna who supported me in this pursuit. Thank you for providing me with guidance through the challenges and obstacles I encountered in my most demanding academic endeavour. Without your experience and care this would have been a lot more demanding than it became. I would also like to thank other staff at Victoria University of Wellington who provided me with the knowledge required to carry out the research process, most notably Todd Bridgman and Bob Cavana. Further thanks to administration staff such as Megan Key who provided swift handling of all of my questions and concerns. Also thanks to the majority of my undergraduate and postgraduate lecturers for providing me with the knowledge from which the base of my ability to tackle this process came.

Finally I would like to acknowledge the importance of my friends and family who provided me with the support needed to undertake this endeavour. To my mother, father, nana and poppa who instilled in me the need to achieve things such as this thesis from a very young age. Thank you for supporting me throughout my four and a half years of study. My friends who provided me with the social support that is essential to maintain a balanced life whilst undertaking the research process, especially Asanga, Stefan, and Oliver who even did the honour of reading over my final draft. 


\section{Table of Contents}

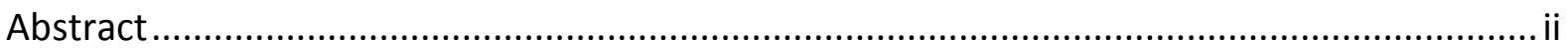

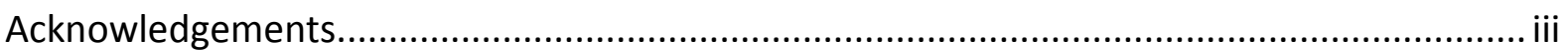

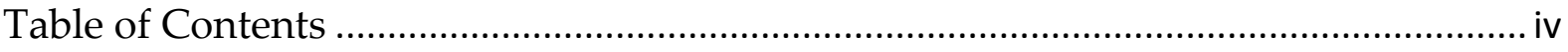

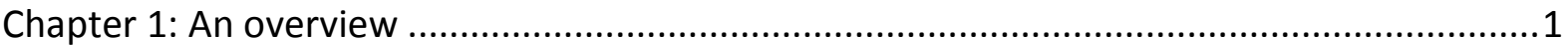

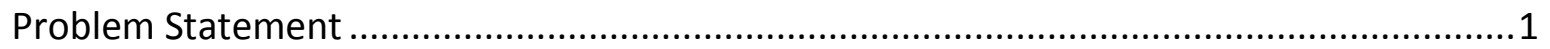

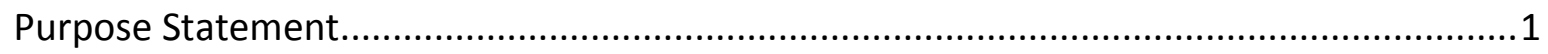

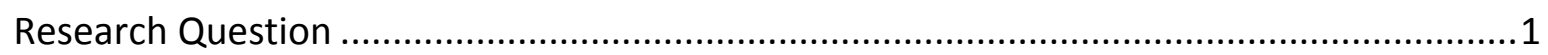

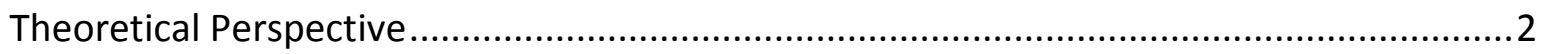

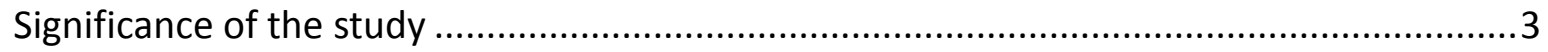

Chapter 2: A background of the relevant Literature .........................................................

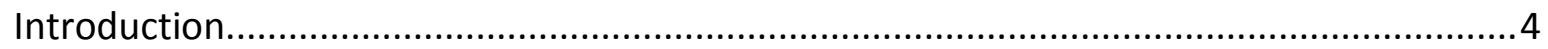

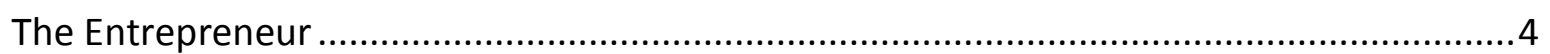

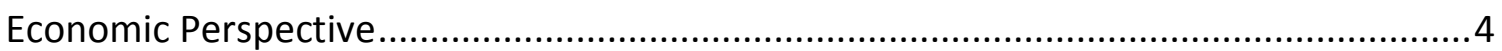

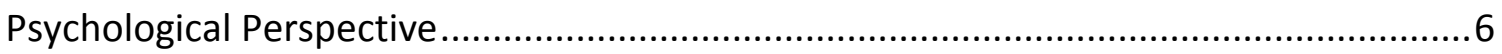

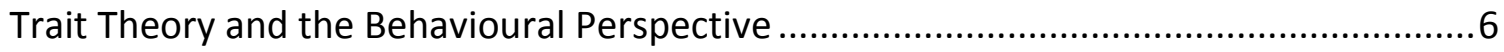

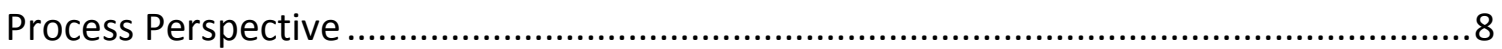

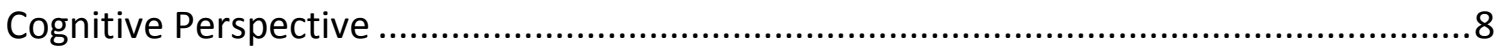

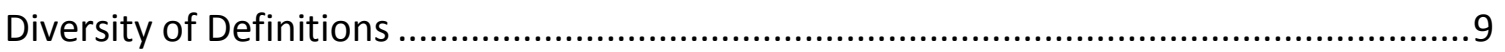

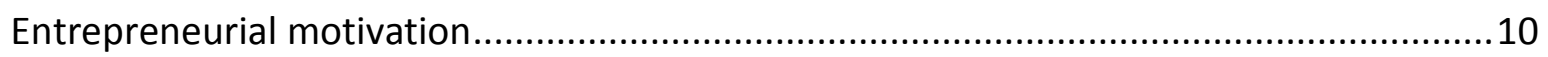

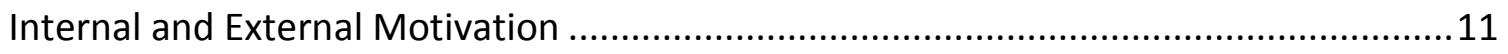

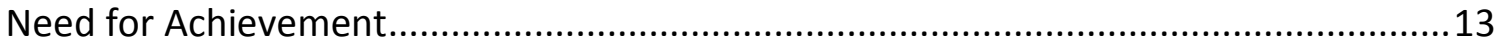

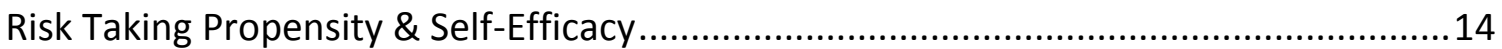

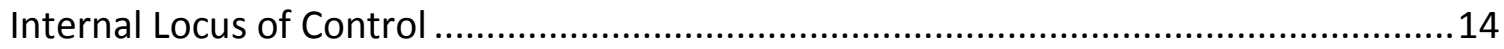

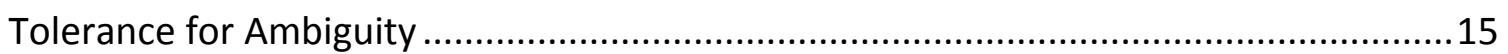

The Theory of Planned Behaviour and Shapero \& Sokol's model of the

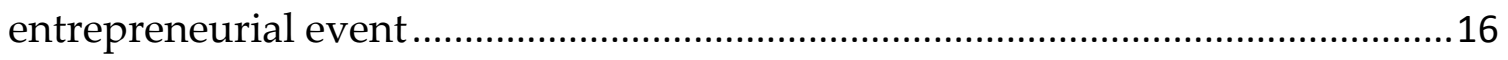

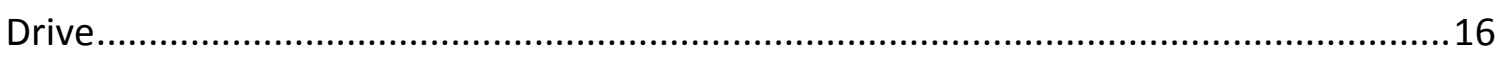

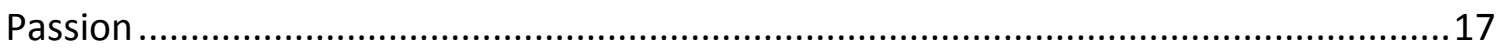

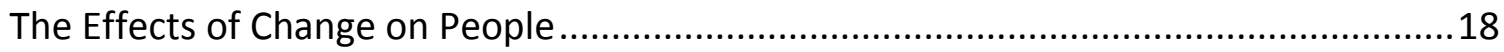

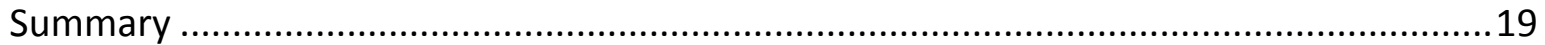

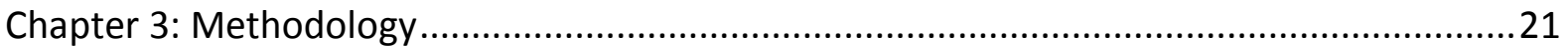

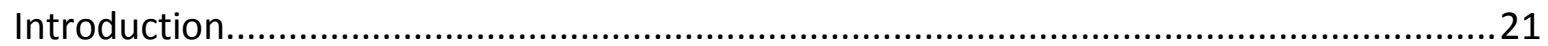




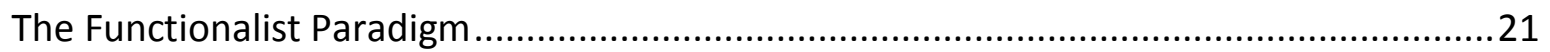

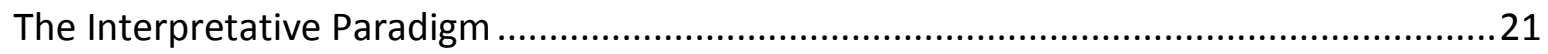

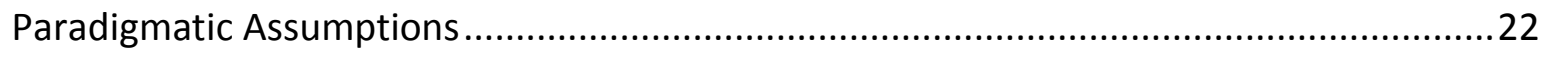

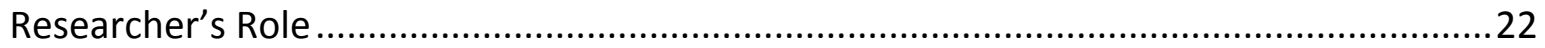

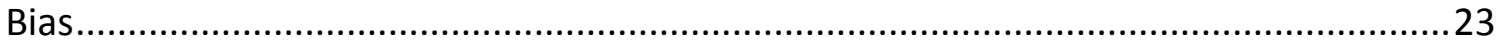

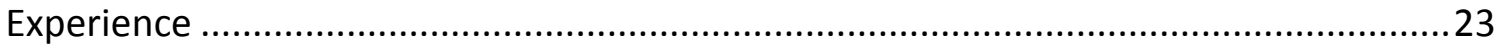

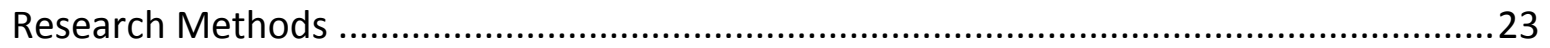

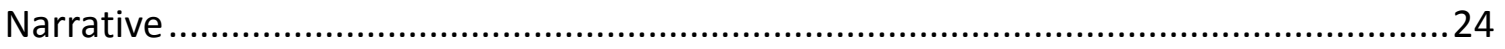

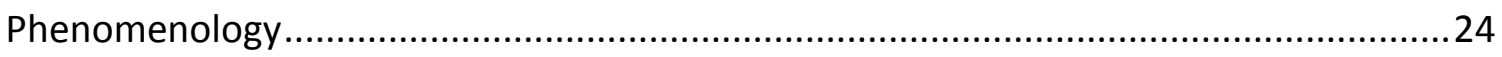

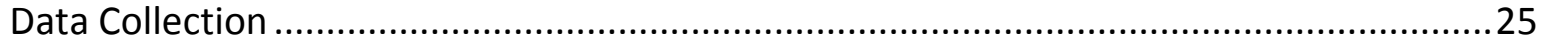

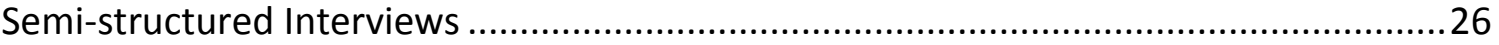

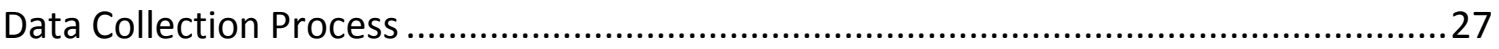

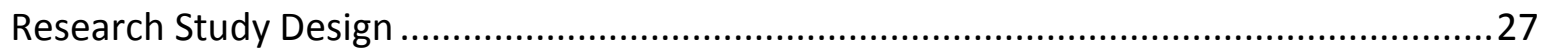

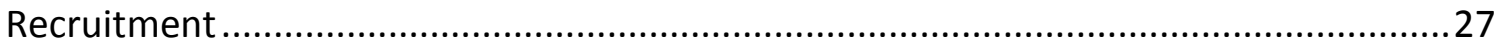

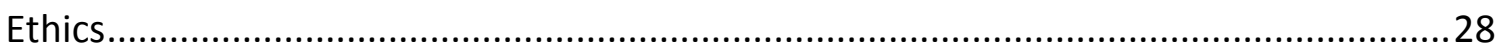

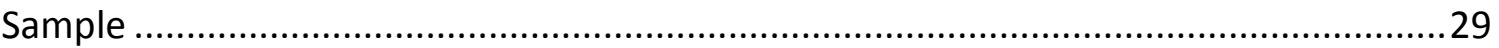

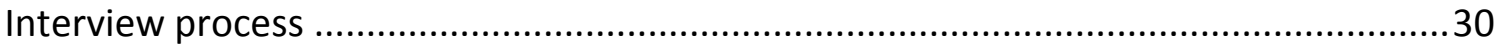

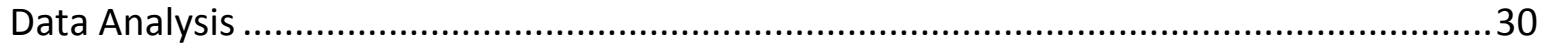

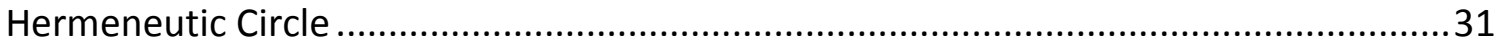

Steps of Interpretative Phenomenological Analysis....................................................... 31

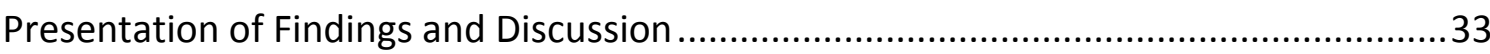

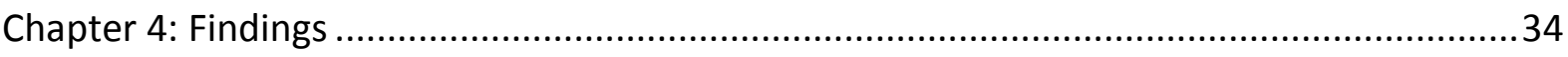

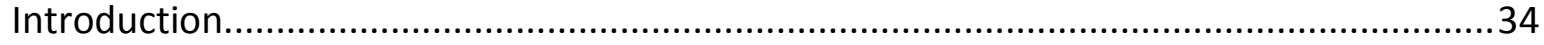

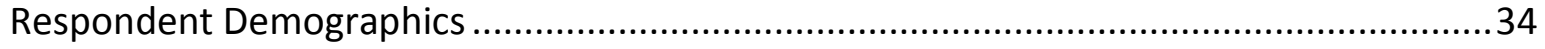

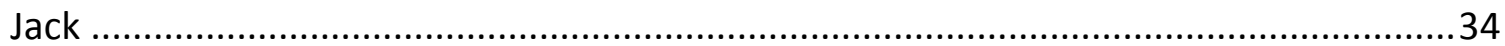

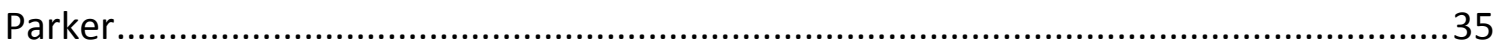

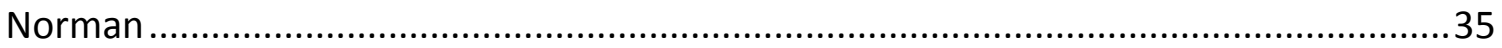

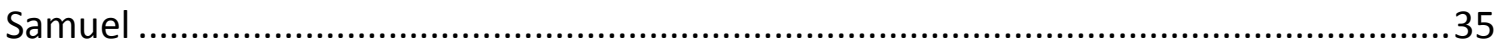

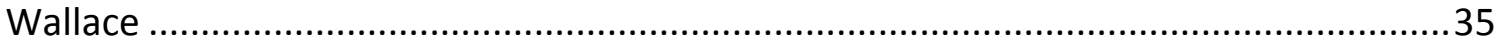

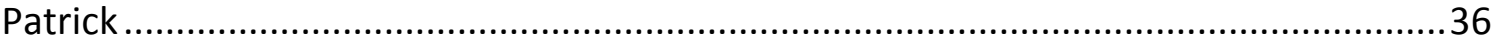

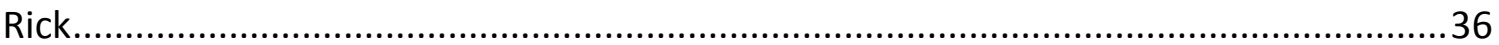

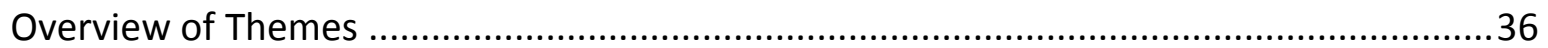

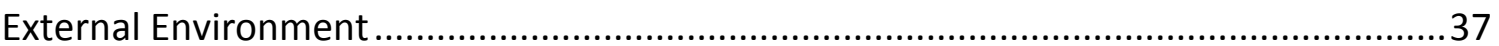




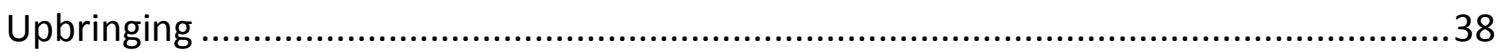

Drive

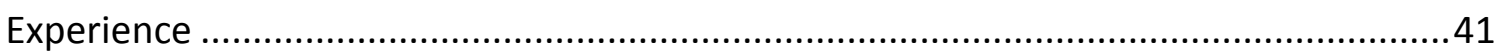

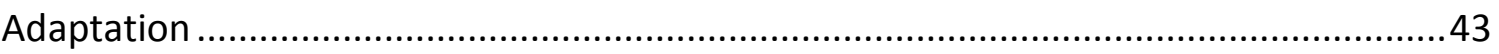

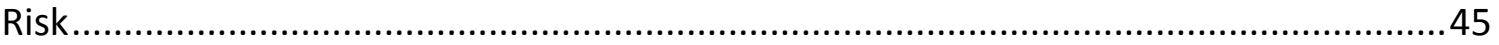

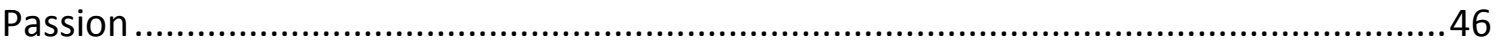

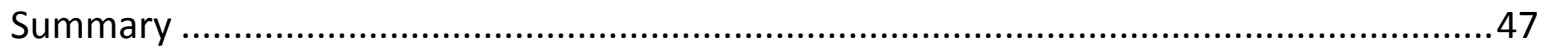

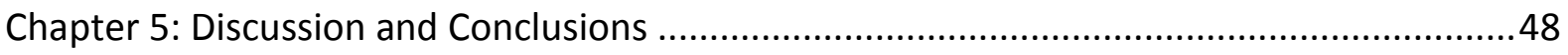

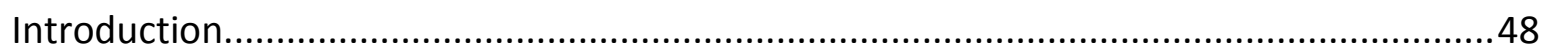

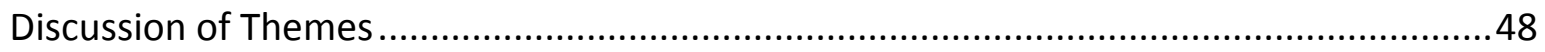

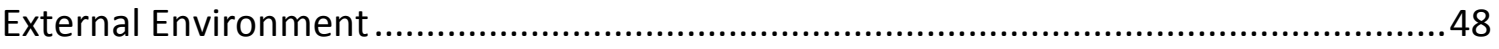

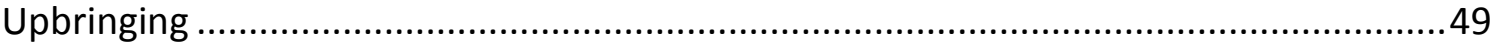

Drive

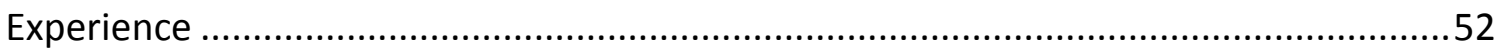

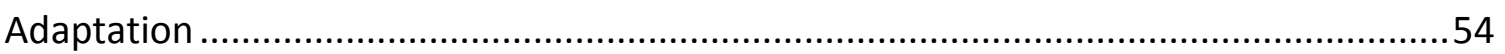

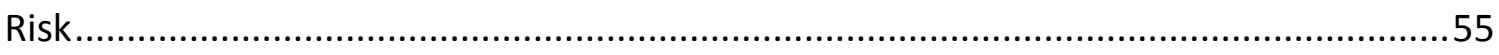

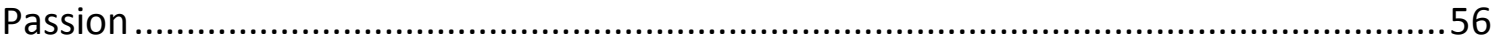

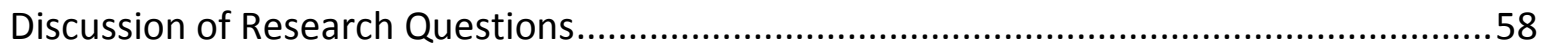

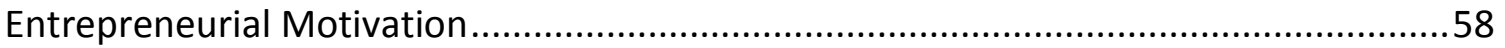

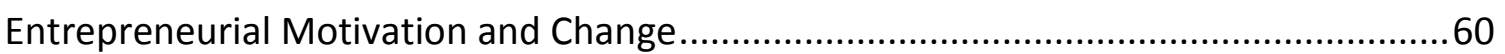

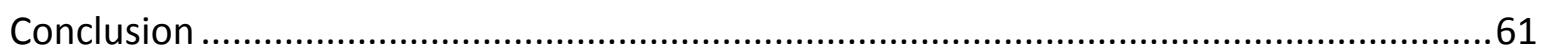

Interpretation of the relationship between entrepreneurial motivation and change ....62

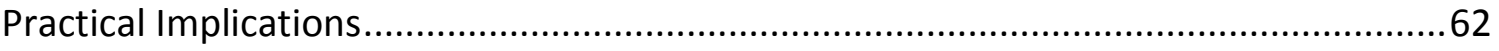

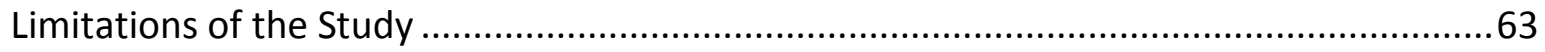

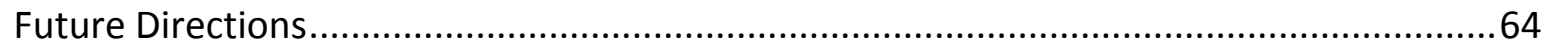

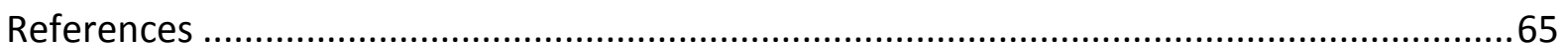

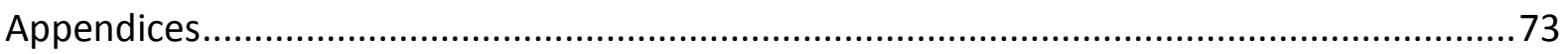

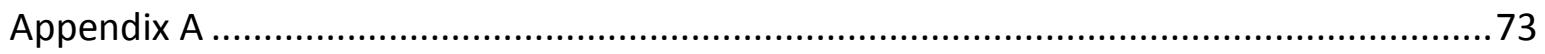

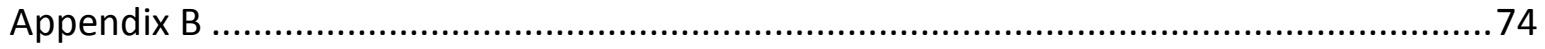

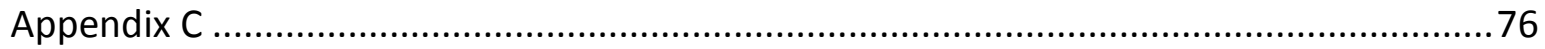




\section{Chapter 1: An overview}

\section{Problem Statement}

Entrepreneurial motivation has been extensively researched and discussed. Understanding how individuals perceive the external environment in relation to their internal beliefs, in deciding to engage in entrepreneurship, has provided knowledge of what drives the entrepreneurial process (Shane, Locke, \& Collins, 2003). However, there is not enough understanding of how entrepreneurs experience motivation over the changing contexts of life (Carsrud \& Brannback, 2011). This lack of understanding about the relationship between motivation and change requires exploration in order to further develop our understanding. This study seeks to explore what entrepreneurial motivation is and how it is affected by change.

\section{Purpose Statement}

The objective of this thesis is to explore entrepreneurial motivation and change. It does this through semi-structured interviews which aim to generate narratives about the phenomena. An interpretative phenomenological approach is taken in the analysis of what entrepreneurial motivation is, and how it is affected by change. This relationship between motivation and change is inherent in the constantly changing circumstances of the entrepreneurial process; however the nature of this relationship is less well known (Carsrud \& Brannback, 2011). An exploration of the relationship between an entrepreneur's motivation and their lived experience of change is carried out in order to provide further knowledge of this relationship.

\section{Research Question}

The generation of further knowledge about the relationship between entrepreneurial motivation and change is of interest to scholars and practitioners. It is unknown whether entrepreneurs adapt their motivations to change or remain motivated regardless of circumstance. The answer to the central research question proposed by this thesis has possible practical implications. These implications may affect the predictive power of entrepreneurial intentions and success for educators, consultants and those considering entrepreneurship (Krueger, Reilly, \& Carsrud, 2000). This study seeks to explore the relationship between entrepreneurial motivation and change in order to improve understanding of those phenomena. Leading from these motivations and objectives the central research question of my thesis is:

\section{"What is entrepreneurial motivation and how is it affected by change?"}


The central aim in exploring this question is to develop a greater understanding of the relationship between entrepreneurial motivation and change. As stated above entrepreneurial motivation has been extensively researched and discussed. However the relationship between entrepreneurial motivation and change still requires further study (Carsrud \& Brannback, 2011). Entrepreneurial motivation has thus far been viewed through a static lense of measuring individuals across behavioural dimensions at a single point in time (Audretsch, 2012). In order for us to develop a complete understanding of the entrepreneur, it may be useful to explore what their experience of motivation is, and how that experience is affected by change. An understanding of the relationship between entrepreneurial motivation and change may provide further insight into the entrepreneurial mind. It is for these reasons that I aimed to pursue understanding of the relationship between entrepreneurial motivation and change.

\section{Theoretical Perspective}

My beliefs about knowledge will determine how this study is conducted. The importance of the researcher's epistemological and ontological world views in the research process is well established. These assumptions and perceptions guide the research methods and knowledge generated from those methods. Because of this it is important to address the paradigm from which I explored the relationship between entrepreneurial motivation and change. I position myself within an interpretivist paradigm seeking to understand the world as it is, viewing "the nature of the social world at the level of subjective experience" (Burrell \& Morgan, 2005, P. 28). This section will discuss the implications of this paradigm on how I can know reality, and what I think reality is, in order to ground research methods in my world view.

I seek to explore the phenomena under investigation at the level of individual consciousness. This is due to my belief that knowledge of the social world is constructed at the level of one's lived experience. This belief stems from the idea that the reality of an object is always dependent on a subject, which means that the objective reality of a phenomenon is dependent on its existence within our subjective consciousness (Moustakas, 1994). Through multiple narratives of experience, about the same phenomenon, we can come to some general understanding of that phenomenon (Guba \& Lincoln, 1994). Because of this belief my findings will be subjectively affected by my role as facilitator and interpreter of lived experience.

I perceive reality as an emergent social process constructed by individuals adopting shared meanings of the world. I aim to generate an understanding of these socially constructed meanings. I believe that this can be achieved through analysing the 
language people use to describe lived experience. The interpretation of these descriptions has more meaning as increasing numbers of people share similar experiences (Bowe \& Sloan, 2014). An interpretative approach to analysing the stories people tell about their experiences leads to understanding of what is experienced and how it is experienced. This uncovers general meanings about the phenomena under investigation, providing some knowledge of how and what it is. Through interpreting lived experience of a phenomenon, I construct some general understanding of that phenomenon.

These beliefs about knowledge drive an interpretative approach to the exploration of knowledge. Within this paradigm knowledge is generated through drawing meaning from multiple respondents who have experienced a phenomenon in an attempt to get closer to a universal understanding of that phenomenon. This process involves interpretation of the phenomena, which requires the researcher to be a participant in knowledge creation rather than an objective observer. This is because I see reality as socially constructed at the level of individual consciousness, through social interaction. These beliefs have led me to take an interpretative phenomenological approach to data analysis with aspects of narrative in data collection.

\section{Significance of the study}

An understanding of entrepreneurial motivation and change is of importance to both scholars and practitioners. Through further understanding these phenomena we can gain insight in to the entrepreneurial mind. Greater understanding of entrepreneurial motivation may provide benefits to teachers, consultants, advisors, and entrepreneurs in terms of predicting individual propensity and viability of entrepreneurship (Krueger, Reilly, \& Carsrud, 2000). Understanding how founder's motivations, beliefs, intentions and perceptions coalesce could provide practitioners and teachers of entrepreneurship greater diagnostic power of entrepreneurial ability (Audretsch, 2012). Providing some understanding of the relationship between entrepreneurial motivation and change also contributes to the current literature, through addressing the gap in knowledge with regards to this relationship (Carsrud \& Brannback, 2011). Generating understanding about how these phenomena are experienced provides relevant implications for both practitioners and scholars. 


\section{Chapter 2: A background of the relevant Literature}

\section{Introduction}

In order to gain understanding in to the relationship between entrepreneurial motivation and change the relevant literature is reviewed. In this section I present what has been said of the entrepreneur in order to demonstrate a diversity of definitions, from the economic perspective through to the cognitive perspective. Once a broad enough understanding of the entrepreneur has been developed entrepreneurial motivation is discussed. This discussion of entrepreneurial motivation is then related to the literature on the effects of change on people. Through reviewing the extant literature I seek to provide an adequate starting point to explore the relationship between entrepreneurial motivation and change in subsequent chapters.

\section{The Entrepreneur}

Entrepreneurship has been described as "a broad label under which a hodgepodge of research is housed" (Shane \& Venkataraman, 2000, P. 217). The study of entrepreneurship originated in economics and spread to multiple fields over the decades. Today research on entrepreneurship has defined the entrepreneur in many ways, with researchers from different disciplines understanding and researching the phenomenon differently. This differentiated understanding of entrepreneurship, stemming from a multiplicity of disciplines, provides scholars with a rich and dynamic field of study (Audretsch, 2012). The following section explores how different fields of study have defined the entrepreneur and entrepreneurship in order to come up with a definition that fits within the scope of this thesis.

\section{Economic Perspective}

The entrepreneur is a factor in microeconomics that has been defined in multiple ways. Entrepreneurship has been described in economics as "a variation of decisions and actions that lead to changes in the division of labour in pursuit of an individual's economic goals" (Michael, 2007, P. 287). The economist Joseph Schumpeter defined entrepreneurs as those willing and able to convert a new idea or invention into a successful innovation (Schumpeter, 1942). Schumpeter saw the entrepreneur as an innovator, on which economic development, growth and progress relied upon, because change in life always seemed to begin with a forceful individual. The field of economics has further developed the idea of the entrepreneur over a long history. 
When discussing the economic perspective of the entrepreneur we are discussing the economic factor that drives innovation and growth, 'the third man'. This individual operates between the owner and the manager, jumping at opportunities and exploiting them through the use of his or her ability to deploy resources (PierreAndre, 1989). From the economic perspective Innovation is seen as the main determinant of firm creation and survival (Baumol, 1968). Entrepreneurs are the theoretical drivers of this innovation, with their activities said to play a key role in economic development (Baumol \& Strom, 2007). This perspective comes from Schumpeter's influential theory of "creative destruction" (Schumpeter, 1942, P. 81). From this view the entrepreneur drives 'creative destruction' through innovation which in turn drives economic growth, development and progress. The entrepreneur's function in the economy is to identify opportunities and exploit them (Schumpeter, 1942). In economic theory the focus is on the entrepreneur as an important driver of innovation and economic growth.

The study of entrepreneurship at the microeconomic level looks at entrepreneurship in relation to organisational context. This perspective describes the context in which these entrepreneurial firms operate and drive growth. In the organisational context of entrepreneurship whether a firm is entrepreneurial depends on criteria such as size, age, and level of self-employment (Audretsch, 2012). Entrepreneurship is seen here as useful in studying new venture formation and economic growth through organisational context and performance criteria (Michael, 2007). In economics the entrepreneur's function is to locate new ideas and put them in to effect, the entrepreneurs cognition and motivations all lead towards taking action in the world, and through this action they give rise to an organisation (Bird \& Schjoedt, 2009). The organisations they give rise to are the focus of study at the level of organisational context. The study of entrepreneurship in economics is largely focused on innovations role in organisation creation, growth, performance, and survival.

Due to this focus on entrepreneurship as a factor in microeconomics, rather than a human phenomenon, the economic perspective has been criticized for not being based on 'reality'. It has been suggested that because numerous studies focus on the level of innovative activity as what determines the level of entrepreneurship that a very narrow picture of the phenomena of entrepreneurship has been provided (Baumol W. J., 1968). In an entrepreneurial economy decision makers realize that in some ways the external reality in which they operate is ambiguous and creative (Davidson, 1996). This is why the internal reality of the individual may provide deeper insights in to the nature of the entrepreneur beyond economic theory. For 
this reason scholars from other disciplines have studied the entrepreneurial mind in an effort to better understand these individuals.

\section{Psychological Perspective}

The psychological perspective moves away from an abrupt focus on innovation to provide insight in to the entrepreneurial mind. Psychologists have studied entrepreneurship at the level of individual behaviour with a focus on the characteristics that set entrepreneurs apart from non-entrepreneurs (Atkinson, 1957). Research taking a psychological perspective makes individual's the main subject of inquiry, looking at how psychological constructs affect business formation and success (Frese \& Gielnik, 2014). This perspective has focused on the personality characteristics and cognitive attributes of entrepreneurs, proposing that entrepreneurial success stems from psychological factors. These factors form individual personality and the creation of goals and strategies in relation to the environment, which have been proposed to lead to entrepreneurial success (Frese \& Rauch, 2000). It is these certain behaviours stemming from individual personality that lead the entrepreneur to recognize opportunities, and pursue those opportunities (Shane \& Venkataraman, 2000). The idea that the entrepreneurial mind may be essential in leading to innovation and organisation creation has been an important stepping stone in entrepreneurship research.

\section{Trait Theory and the Behavioural Perspective}

From a behavioural perspective the entrepreneur is defined by the behaviours that they exhibit in the creation of new firms. This is opposed to the trait approach which views entrepreneurs as a set of traits inherent in them to some degree (Gartner, 1989). The behavioural approach to entrepreneurship holds organisational context constant. This is done whilst looking at how the cognitive processes and mental models of individuals within these organisations differ across dimensions of entrepreneurial behaviour (McClelland, 1961). Building on Schumpeter's view of the entrepreneur as an innovator, and criticizing the trait theory of entrepreneurship, Peter F. Drucker defined the entrepreneur from a behavioural perspective as one who searches for and responds to opportunities as they appear (Drucker, 1985). Responding to opportunities for economic exploitation is the main behaviour exhibited by the entrepreneur.

David McClelland (1961) described the entrepreneur as one who has a high need for achievement, is energetic and is a risk taker. His research led to the trait theory of entrepreneurship, which studies entrepreneurship at the personality level. This theory defines the entrepreneur as one whose unique personality characteristics such 
as a high need for achievement, high risk taking propensity and internal locus of control lead them to engage in entrepreneurship. The influence of personality traits on the individual's decision to become, and stay, self-employed found some grounding in this field of study (Collins, Hanges, \& Locke, 2004). The trait theory of entrepreneurship became very popular, and also came under a lot of criticism. This criticism led to other perspectives from which to understand the entrepreneurial mind.

There has been a large amount of debate amongst scholars about whether personality traits affect one's entrepreneurial nature. Gartner (1989) argued that the study of entrepreneurship from a traits perspective fails to take in to account what entrepreneurship is. His view proposed looking at entrepreneurship as a set of behaviours rather than inherent traits. This debate has led to many dismissing the personality approach due to mixed results in the data (Carsrud \& Brannback, 2011). The opposing argument is that entrepreneurs need not just knowledge and expertise in business but also the abilities, behaviours and values that are influenced by personality traits (Delgado-Garcia, Rodríguez-Escudero, \& Martín-Cruz, 2012).

In a study by Delgado-Garcia et al. (2012) it was found that personality characteristics significantly influence the likelihood of an individual's decision to become an entrepreneur, as well as having an effect on the likelihood of their success. Other studies found that 'personality significantly influences entrepreneurial choices and entrepreneurial processes' (Caliendo, Fossen, \& Kritikos, 2011). Trait theory proposes that we can identify entrepreneurs according to certain personality characteristics; with the influence of multiple personality traits, such as extroversion, being found to significantly determine entrepreneurial potential (Zeffane, 2013). This focus on traits stems from the idea that traits lead to behaviours. The idea that looking at behaviours rather than traits is a better way to study entrepreneurship seems unfounded; because behaviours are the external manifestation of personality traits.

Whether the focus should be on behaviours or traits, it is clear that certain characteristics affect entrepreneurial behaviour and success. Concepts like locus of control (Rotter, 1966) and risk attitudes (Brockhaus R. , 1980) have found some grounding in their effect on the individual's decision to become, and stay, selfemployed. Other influential scholars have emphasized the influence of personality traits on entrepreneurial decisions and behaviour. Personality traits have an important place in the literature in terms of our understanding of what makes an entrepreneur (Carsrud \& Brannback, 2011). For these reasons it is fair to believe that 
through studying an individual's values, beliefs and behaviours we can gain a greater understanding in to the entrepreneurial mind.

\section{Process Perspective}

Whether looking at traits or behaviours it is still important to return to the actions of entrepreneurship when searching for what makes the entrepreneur. One way of studying the actions entrepreneurs take is to study the process of entrepreneurship. From this perspective scholars have defined entrepreneurship as a "process of recognising and pursuing opportunities with regard to the alienable and inalienable resources currently controlled with a view for value creation" (Chell, 2007, P. 18) or as a process where "individuals and groups of individuals seek and exploit economic opportunity" (McKenzie, Ugbah, \& Smothers, 2007, P. 29). The process of entrepreneurship takes place through innovation, which is the tool that an effective entrepreneur uses to convert a source into a resource (Drucker, 1985).

However the process perspective has received some criticism, with researchers arguing that being innovative does not explain why some individuals are entrepreneurs and others are not, even if it is a necessary prerequisite to entrepreneurship (Caliendo, Fossen, \& Kritikos, 2011). An individual's innate temperament and behaviour is a greater predictor of entrepreneurial potential than the skills that they possess, such as the ability to write a business proposal (Thompson, 2004). Whatever perspective is taken with regard to what makes an entrepreneur, it is clear that the process of starting a business is an essential component. This is why looking at what it takes for an individual to engage in this process may shed light on what makes some individuals entrepreneurial in nature. Why some individuals are entrepreneurs and others not may also be determined by the cognitive ability and style they possess, which may make them more adept at engaging in the entrepreneurial process.

\section{Cognitive Perspective}

The cognitive perspective of entrepreneurship came in response to the limitations of the trait perspective. Whilst the psychological and trait perspectives paved the way for research in to the entrepreneur as an individual the cognitive perspective expanded further. Researchers based in cognitive psychology attempted to differentiate entrepreneurs by "the way they think and process information differently" (Sanchez, Carbello, \& Gutierrez, 2011, P. 433). Researchers in the area believe that we can understand entrepreneurial behaviour based on individual differences in cognitive structure and processes. This is argued because how an individual assimilates and utilizes knowledge is theorized to determine the actions 
that they will take (Carsrud, Brannback, Elfving, \& Brandt, 2009). Rather than focusing on inherent traits or entrepreneurial behaviour, the cognitive approach focuses on the way individuals think in determining how they will behave.

These cognitive structures and processes may explain why some individuals exploit opportunities. Within the cognitive approach self-efficacy beliefs and intentions have been found to be the most important predictors of entrepreneurial behaviour (Sanchez, Carbello, \& Gutierrez, 2011). The role of emotions in entrepreneurial behaviour has also been found to be significant in a study on goals, such as exploiting opportunities (Delgado-Garcia, Rodríguez-Escudero, \& Martín-Cruz, 2012). The influence of entrepreneurial motivation on an individual's self-concept has been related to their ability to persist and move in to the role of 'founder'. This is because "identity helps individuals orient to the founding context... identity influences behaviour even before individuals come to occupy the role" (Hoang \& Gimeno, 2010, P. 42). This may mean that entrepreneurial motivation leads individuals to exploit opportunity through adopting an entrepreneurial identity. This identity involves cognitive structures and processes which aid in entrepreneurial success.

Identity has also been found to be an important part of an individual's decision to become an entrepreneur. The construction of identity affects the entrepreneurial process through affecting how the entrepreneur perceives opportunities, generates resources, and approaches new people (Nielsen \& Lassen, 2012). For an entrepreneur to adopt the behaviours that lead to successful entrepreneurship the transition of identity to being an entrepreneur must be successful. Individuals continually construct this identity, or sense of whom they are. A change in circumstance such as founding a company may require them to conceptualize their sense of self differently, in order to be successful (Farmer, Yao, \& Kung-Mcintyre, 2011). Whether a person's conceptualisation of their identity matches up with what they perceive to be entrepreneurial can help determine those who start and continue to run their own ventures and those who do not. The idea of a possible self, such as the desire to be an entrepreneur, has been found to have powerful effects on the likelihood that an individual will engage in entrepreneurial activity.

\section{Diversity of Definitions}

From the above discussion there are common ways of defining entrepreneurship and the entrepreneur in all perspectives. There is focus on who the entrepreneur is, what they do, the exploitation of opportunities, and the innovation that stems from this exploitation. The definition chosen combines all of these commonalities in the 
literature. This definition is taken from a review of the entrepreneurship literature by Shane and Venkataraman (2000). Their definition takes in to account the failures of defining the entrepreneur at the organisational and behavioural levels separately. They define the field of entrepreneurship research as "the scholarly examination of how, by whom, and with what effects opportunities to create future goods and services are discovered, evaluated, and exploited" (P. 172). Rather than describing what characterisitcs differentiate some individuals from others, this definition focuses on the tendency of some individuals to respond to certain opportunities in the market. With a definition of entrepreneurship that focuses on the exploitation of resources I must define the entrepreneur in the same manner, through using a definition picked from a range of perspectives.

As noted by Rauch and Frese (2000) the relevant literature on the entrepreneur is distributed across numerous journals adopting different perspectives on the topic. The diversity of views on what constitutes entrepreneurship creates a richness and diversity of understandings, which is what makes the field so dynamic (Audretsch, 2012). Due to this broad range of definitions an operational definition should be provided to describe what is meant when discussing the entrepreneur. Whatever definition is chosen, there are certain actions that need to be taken in order for an individual to be considered entrepreneurial. The individual must recognize an opportunity in the market and have the ability/desire to capitalize on that opportunity through organising a venture that engages in the exploitation of that opportunity (Shane \& Venkataraman, 2000). This thesis operationally defines the entrepreneur as 'An individual that recognizes an opportunity in the market and deploys resources in the pursuit of exploiting that opportunity through the creation of an organisation'. I came to this definition through Shane \& Venkataramans' (2000) review of literature on the entrepreneur from multiple disciplines.

\section{Entrepreneurial motivation}

In this section I provide an overview of some of the more prevalent characteristics in the extant literature on entrepreneurial motivation. The section first makes a distinction between internal and external factors of motivation, then focusing in on internal factors due to my studies focus on the entrepreneurial mind. These internal and external factors combine to affect the motivation an individual feels towards engaging in entrepreneurship. Some internal personality factors like a need for achievement are inherent from a young age, whilst others such as self-efficacy are developed through experience. The focus on personality characteristics is supplemented with a discussion of entrepreneurial behaviours and their relationship 
with change through the theory of planned behaviour and the effects of change on people. These characteristics and factors affecting entrepreneurial motivation shed some light on what it is, and how it is affected by change.

Entrepreneurs have the ability to both recognize an opportunity and deploy resources to exploit it. The intention to exploit an opportunity may be present, but in order for someone to take action there must be sufficient motivation to do so. From this view an individual may have entrepreneurial traits, but without the link between intention and action that individual will not take the risk of exploiting those opportunities (Ajzen, 1991). Motivation is the link between intention and action (Carsrud \& Brannback, 2011). It can be supposed that without motivation occurring the individual will not engage in entrepreneurial activities. Because of this, motivation has gained a lot of attention as the link between possessing certain entrepreneurial characteristics and taking the action of exploiting an opportunity; motivation is required for the entrepreneur to engage in organisation creation. This is one reason why an understanding of entrepreneurial motivation has been deemed an important area of study.

The study of entrepreneurial motivation has provided many insights in to entrepreneurial behaviour (Carsrud \& Brannback, 2011). Some of these studies attempt to explain these entrepreneurial intentions through internal factors such as personality traits, like a propensity for taking risks (Caliendo, Fossen, \& Kritikos, 2011). Others have looked at age related motivations, finding that an individual's personal goals and concerns reflect the developmental task of their own age (Nurmi, 1992). Decisions are made at the level of goals and then at the level of actions to attain those goals. Whether an individual takes the actions to achieve a goal depends on the level of desire they feel towards that goal. Emotional states may also provide individuals with the impetus towards goal striving and enacting those goals (Bagozzi, Dholakia, \& Basuroy, 2003). Through studying entrepreneurial motivation understanding of the internal and external factors that drive entrepreneurial behaviour has been developed. There have been many attempts to explain entrepreneurial behaviour through internal and external factors of motivation, providing improved understanding of the entrepreneurial mind.

\section{Internal and External Motivation}

The research on motivation has separated the factors that make up the phenomena into internal factors and external factors. As the entrepreneur goes through life there is some relationship between internal motivations and effects from the external environment (Jayawarna, Rouse, \& Kitching, 2011). The motivation literature has 
had difficulties defining motivation, however most definitions include aspects of activation, direction, and maintenance of behaviour (Ambrose \& Kulik, 1999). Whether looking at the stage of life or their personality, it is clear to us now that individuals are affected by both internal and external sources of motivation (Schultheiss, Strasser, Rosch, Kordik, \& Graham, 2012) with both forms of motivation having an influence on the decision to start a business (Taormina \& KinMei Lao, 2007). The most successful individuals in any endeavour are able to balance both extrinsic and intrinsic motivation factors in the right way, in different contexts, and at different times (Sansone \& Harackiewicz, 2000). Entrepreneurial motivation is affected by the individual's internal world and their external environment.

Extrinsic factors of motivation have been extensively researched in the field of psychology. External influences develop during the entrepreneurs' life course that can result in the need to engage in self-employment (Jayawarna, Rouse, \& Kitching, 2011). Grundsten (2004) looked at how the environment affected entrepreneurial behaviour, finding that affective and rational environmental factors affect entrepreneurial intentions. Studies have looked at these external factors of motivation, with important findings including that the external monetary rewards of entrepreneurship are not nearly as powerful as the internal non-monetary rewards (Alstete, 2008). The decision to become an entrepreneur across career course is influenced by the authenticity, balance and challenge provided by their current profession (Sullivan, Forret, Mainiero, \& Terjesen, 2007). From this research it is clear that external factors of motivation have an effect on the entrepreneurial mind.

Shapero \& Sokol (1982) described these external factors as social and situational mechanisms coming together to explain the decision to become an entrepreneur. These social and situational mechanisms include professional and personal background, experience, and perceived feasibility of self-employment. These factors are also related to other personal and professional external factors such as personal goals, business environment and the business idea (Naffziger, Hornsby, \& Kuratko, 1994). External factors are important in that they often drive the decision to become an entrepreneur; however it seems to be the internal factors that drive the individual throughout the entrepreneurial journey.

The literature largely focuses on internal factors driving entrepreneurs in to selfemployment. These factors include enjoying the freedom, job satisfaction and money that come with entrepreneurship. However there are also negative factors such as stress, risk, and responsibility which affect the decision (Alstete, 2008). An individual's perceived motivation and intentions to become an entrepreneur are 
mediated by that individual's perceived behavioural control and attitudes (Solesvik, 2013). Internal factors such as personality characteristics (Caliendo, Fossen, \& Kritikos, 2011), psychological factors (Brockhaus R. H., 1982) and even biology (White, Thornhill, \& Hampson, 2006) affect these motivations. The research undertaken here largely focuses on the intrinsic factors within an individual that provide the link between intention and action (Carsrud \& Brannback, 2011).

The literature on intrinsic factors of motivation has been largely influenced by 'SelfDetermination theory', which was developed by Edward Deci and Richard Ryan (1975). This theory suggests that people tend to be driven by a need to grow in order to gain fulfilment; this need manifests itself in the form of people's inherent growth tendencies. Internal motivations help us to explain why individuals strive towards growth. Self-determination theory assumes that people are activity directed towards growth. This growth is achieved through gaining mastery over challenges and taking in new experiences. Deci and Ryan identify competence, relatedness and autonomy as generating intrinsic motivation through developing a cohesive sense of self (Ryan \& Deci, 2000). This internal drive to grow and master challenges may be an important aspect of entrepreneurial motivation.

How intrinsically motivated an individual is will determine the level of energy and commitment they apply to attaining goals. It is the need to achieve these things that drives individuals towards self-development. This intrinsic motivation leads to intrinsic regulation which in turn allows individuals to take action. Intrinsic motivation is the best indicator of whether an individual will take action towards growth versus being inclined to remain passive and stagnate (Bee, Koh, \& Wang, 2012). In the entrepreneurial motivation literature scholars have identified numerous personality characteristics and internal factors that drive the entrepreneur in to action (Shane, Locke, \& Collins, 2003). An overview of some of these intrinsic motivation factors is given in the following sections.

\section{Need for Achievement}

Need for achievement (NAch) is an internal motivation factor that has received a lot of attention in the literature. McClelland (1961) first identified the construct describing that need for achievement is the level of desire an individual has for significant accomplishment. Individuals high in Nach seek out situations in which they have direct control over outcomes, and receive feedback for their behaviour (McClelland D. C., 1961). Due to entrepreneurial roles being characterized by the above attributes it has been proposed that individuals with high NAch would be more likely to engage in entrepreneurial activities (Owoseni, 2014). A study found 
that need for achievement significantly determines entrepreneurial potential (Zeffane, 2013). Furthermore an individual's degree of NAch has been found to be significantly related to that individual engaging in entrepreneurial activities (Collins, Hanges, \& Locke, 2004). NAch is a very useful differentiator when comparing entrepreneurs to the general population and going further may help to explain the occurrence of success and failure in an individual's entrepreneurial activities (Carsrud \& Brannback, 2011). It seems that having a need for achievement leads to individuals starting businesses, and continuing to run them successfully. This would make it an important factor in the relationship between entrepreneurial motivation and change, explaining why individuals are internally motivated.

\section{Risk Taking Propensity \& Self-Efficacy}

Risk Taking propensity has been proposed to be an essential factor in explaining an individual's decision to engage in entrepreneurial behaviour. This concept emerged from McClelland's research on the entrepreneur. McClelland claimed that individuals high in NAch would have a moderate propensity for risk taking, because these factors both relate to the individuals self-efficacy or perceived behavioural control in relation to uncertainty (McClelland D. C., 1961). Individuals high in NAch may also be moderate risk takers due to the challenge generated by ambiguity appealing to both motivations (Atkinson, 1957).

Some studies have found that risk taking propensity may not be a distinguishable characteristic of entrepreneurs (Brockhaus R. , 1980). However this may be due to measurement of the wrong concept as risk taking propensity may be confounded with an individual's self-efficacy (Shane, Locke, \& Collins, 2003). Self-efficacy is defined as the individual's belief in their ability to succeed in certain situations (Atkinson, 1957). Self-efficacy has been found in multiple studies to have an effect on entrepreneurial intentions (Owoseni, 2014). An individual's intentions are driven by their attitudes and perceived behavioural control, with tolerance for risk significantly predicting an individual's self-employment intentions (Segal, Borgia, \& Schoenfeld, 2005). It seems likely that individuals are able to deal with the risk of entrepreneurship in their minds because they have a belief in their abilities to be successful in spite of the risk involved.

\section{Internal Locus of Control}

Another important factor in the structure of entrepreneurial motivation is internal locus of control. This is the belief that one's actions will have a direct impact on the expected outcomes of those actions (Rotter, 1966). This research has largely focused on the needs of individuals to be independent, free and self-directing (Harrell \& 
Alpert, 1979). It has been found that individuals with a high locus of control are more likely to be entrepreneurs than members of the general population (Shane, Locke, \& Collins, 2003). Having an internal locus of control and high level of selfefficacy accurately predicts whether an individual intends to engage in entrepreneurship (Chen, Greene, \& Crick, 1998). The idea that individuals have an inherent desire to control their actions and outcomes may play an important part in entrepreneurial motivation through improving the individual's belief in their abilities.

Self-efficacy may play an important part in the individuals desire to engage in selfemployment or organisation creation. Self-efficacy may be defined as the individual's belief in their ability to produce desired effects through their actions (Bandura, 1986). The positive relationship between entrepreneurial intentions and self-efficacy gives credence to the need for an increased focus on self-efficacy in entrepreneurship research (Naktiyok, Nur Karabey, \& Caglar Gulluce, 2010). The idea that individuals have an inherent desire to control their actions and outcomes may play an important part in entrepreneurial motivation. Having an internal locus of control and a high sense of self-efficacy both seem to be tapping the same construct. Both of these factors may directly relate to an individual's belief in their ability to achieve outcomes through their efforts. This desire to control actions may have a relationship with the desire to engage in self-employment or organization creation.

\section{Tolerance for Ambiguity}

It is clear that most intrinsic motivation factors are somewhat intertwined, and the same is true when we discuss tolerance for ambiguity (Pinillos, 2011). It was defined by Budner as a personality trait characterized by "the tendency to perceive ambiguous situations as desirable" (1962, P.29). This ability to tolerate the risk involved with ambiguity is an important characteristic of the entrepreneur's motivation due to the ambiguous nature of entrepreneurship (Caliendo, Fossen, \& Kritikos, 2011). However others have concluded that we do not yet know if traits are an important differentiator between entrepreneurs and non-entrepreneurs (Shane, Locke, \& Collins, 2003). Tolerance for ambiguity is high for individuals in areas that they feel they can achieve desired outcomes. Like risk taking propensity and internal locus of control, tolerance for ambiguity can also be confounded with self-efficacy. It seems as though these three factors are intertwined to affect the individual's level of self-efficacy. 


\section{The Theory of Planned Behaviour and Shapero \& Sokol's model of the}

\section{entrepreneurial event}

Another important concept in the entrepreneurial motivation literature is the theory of planned behaviour (TPB). The theory proposes that "Intentions to perform behaviours can be accurately determined by an individual's attitudes, subjective norms, and perceived behavioural control" (Ajzen, 1991, P. 179). It allows us to determine which behaviours individuals are likely to engage in, with each factors degree of influence varying between changing contexts; from behaviour to country (Engle, et al., 2010). Furthermore the intentions derived from these factors accurately predict individuals' planned behaviour, which helps explain why so many individuals plan to start a business before an opportunity is discovered (Krueger, Reilly, \& Carsrud, 2000). The theory is able to predict an individual's behaviour quite well. It does this through generating understanding of the individual's attitudes and norms in relation to a specific behaviour, allowing us to tell whether the link between intention and action is present. The theory of planned behaviour has been found to strongly explain and predict the likelihood that an individual will engage in entrepreneurial activities (Krueger \& A., 1993). The theory of planned behaviour illustrates how perceived feasibility and perceived desirability of entrepreneurship will lead to that behaviour. Allowing us to determine why individuals become entrepreneurs.

Shapero \& Sokol's' (1982) model of the entrepreneurial event (SEE) is a similar model also purported to predict the likelihood that individuals will engage in certain behaviours. The model proposes that entrepreneurial intentions depend on the individual's personal desirability, feasibility and propensity to act. However it is not well tested in the domain of entrepreneurship research (Krueger, Reilly, \& Carsrud, 2000). Both SEE and TPB are the most widely used in the study of entrepreneurial intentions. The theory asserts that intentions towards starting a business are largely determined by that individual's attitudes and norms with regards to starting a business (Wurthmann, 2014). These models provide understanding of why individuals are motivated to engage in certain behaviours. This is what makes these theories important when determining why certain individuals decide to engage in entrepreneurship.

\section{Drive}

The concept of drive has been widely discussed in entrepreneurship research. It has been defined and described in many ways. One way of describing entrepreneurial drive is as "a valuable combination of qualities, skills, and attitudes" (Getley, 1979, 
P. 19). This combination of characteristics generates the determination and tenacity of individuals to create new organisations whilst overcoming external barriers to success. Individuals who possess this entrepreneurial drive are determined to achieve to the point of being willing to take risks in order to achieve that thing.

Scholars have looked at how this drive comes about and whether this drive can be developed through entrepreneurial education. One such study found that there is a "rationale for having entrepreneurship courses and workshops in the curriculum of business students" (Vij \& Sharma, 2013, P. 65), because these courses help to develop the student's sense of self-efficacy with regards to entrepreneurship. Other studies have further supported the claim that entrepreneurial drive can be taught or at least fostered in business schools through focusing on attitudes and beliefs with regards to entrepreneurship (Florin, Karri, \& Rossiter, 2007). Entrepreneurial drive somehow leads to superior performance related to making the right strategic choices and overcoming obstacles with tenacity leading to successful entrepreneurship. It seems that drive may be an important factor in determining whether an individual will be successful as an entrepreneur.

One paper supports the proposition that entrepreneurs operating in the "early stages of venture creation and growth exhibit higher entrepreneurial drives than those operating in mature stages" (Armstrong \& Hird, 2009, P. 419). Even once firms have been well established the idea that entrepreneurial drive is positively associated with superior industry performance has been supported (Wood \& Michalisin, 2010). Entrepreneurial drive somehow leads to superior performance related to making the right strategic choices and overcoming obstacles with tenacity, leading to successful entrepreneurship. It seems that drive may be an important factor in determining whether an individual will be successful as an entrepreneur. Research on drive has determined it to be an important part of entrepreneurial motivation, in both early and mature stages.

\section{Passion}

Passion has been said to play an important role in entrepreneurial motivation. The focus has largely been on what passion is and what it does. Studies have defined passion as the love, joy, and enthusiasm that occur as part of the entrepreneurial process, which provides an emotional resource in enabling the entrepreneur to deal with challenges and drive forward (Cardon, Wincent, Singh, \& Drnovsek, 2009). These intense positive feelings towards entrepreneurial activities spur the entrepreneur on in the face of adversity. Passion gives the entrepreneur the energy 
to deal with the challenges and changes encountered throughout the entrepreneurial journey, which may make it an important aspect of entrepreneurial motivation.

This passion for a particular area of business, or business in general, is attached to the entrepreneur's identity. This connection of passion to the entrepreneur's identity creates something very powerful. Conceptualised in this way passion for entrepreneurship is "the consciously accessible, intense positive feelings experienced by engagement in entrepreneurial activities" (Cardon, Wincent, Singh, \& Drnovsek, 2009, P. 517). Studies have shown that passion rises and falls depending on whether the entrepreneur is engaged in the activities they feel passionate towards, as well as affecting the level of self-efficacy the individual feels towards that activity (Murnieks, Mosakowski, \& Cardon, 2014). Entrepreneurial passion occurs in different domains of entrepreneurship (founding, inventing, or developing) and shows up as intense feelings towards the activity because the individual identifies with that activity. The passion that individual's feel towards their business could be what allows these individuals to tackle obstacles and events with energy and enthusiasm which would make it an important factor in the relationship between entrepreneurial motivation and change.

\section{The Effects of Change on People}

In order to understand how entrepreneurial motivation is affected by change we must look at how change affects the self. From most of the literature it is clear that changing contexts do have an effect on our sense of self. Our personality may develop at a young age (Caspi \& Roberts, 2001) but this sense of self continues to change over our life time according to neurocognitive, cultural and social dynamics (Bee, Koh, \& Wang, 2012). Change clearly has profound effects on the self from childhood to middle age, and because of this an individual's ability to conceptualize those changes will affect their own attitudes and behaviours in the process of selfdevelopment (Tetlock \& Levi, 1982). It is clear that changing circumstances often lead to a change in self.

It is important to consider how changing circumstances over the entrepreneur's life are met by changes in the entrepreneur's motivations and goals. As we go through our lives there is both change and continuity in our personalities and the mental models that drive them. Whether changes occur depends greatly on the individual's interaction with the external environment and Internal self (Caspi \& Roberts, 2001). This would infer that in some way the entrepreneur's motivation will be affected by change, but the type of change and to what extent this change occurs will be determined by the individuals' internal and external context. 
Our personalities are largely set in childhood but as we go through life the social actions we take and experiences we have shape this personality greatly (McAdams \& Olson, 2010). Changes occurring across the life span are diverse rather than linear due to the interplay between behaviour, personal factors and environmental events (Lerner, 1990). Change must be embedded in the study of personality, because personality itself is developed through change; it is created by the triadic dynamics of person, behaviour and environment (Bandura, 1986). These experiences create situations in which we must adapt because "Individuals have to adjust to, cope with, and take advantage of the changing opportunities and constraints faced in life" (Heckhausen \& Wrosch, 2010, P. 34). It seems that as individuals go through life and adapt to change, they themselves change, which may have implications for entrepreneurial motivation and change.

We have inherent traits in terms of personality but these do develop over the life course; there will be both continuity and change in ourselves. These internal dimensions of personality typically predict our daily behaviours, thoughts, and feelings across multiple situations. The extent to which change has an effect on internal dimensions of personality will vary between individuals due to genetic differences. The literature concisely shows that the changing contexts of our lives influence the mental models that we operate from; this may suggest fluidity in entrepreneurial motivation as a self-concept (Heckhausen \& Wrosch, 2010). The literature on changes effects on personality would suggest that entrepreneurs are affected by change across their life course, however whether this change affects their motivation is not well established.

\section{Summary}

Entrepreneurs are individuals who recognize an opportunity in the market and deploy resources, in the pursuit of exploiting that opportunity through the creation of an organisation. Entrepreneurial motivation is the drive to engage in the process of starting and running a business. This motivation is made up of internal characteristics and external events that spark the entrepreneurial process. Prevalent internal factors of motivation that drive these individuals to engage in the entrepreneurial process have been extensively discussed in the literature. This thesis largely focused on these internal characteristics due to my interest in what this internal motivation is and what its relationship to change is. It is clear that change has an effect on our personalities, but not so much whether it effects an individual's internal motivation. 
This chapter explored what the entrepreneur is from the perspective of multiple fields of study, before discussing prevalent characteristics that have been used to measure the individual's degree of entrepreneurial motivation in the literature. This chapter developed an adequate understanding of some of the more prevalent factors at play in entrepreneurial motivation, as well as a preliminary understanding of changes effects on people. The entrepreneur and entrepreneurship has been defined, and the internal and external factors that motivate individuals to engage in entrepreneurship have been discussed. This is the position from which I explore entrepreneurial motivation in relation to change. 


\section{Chapter 3: Methodology}

\section{Introduction}

This chapter discusses the methods applied to the research I conducted in exploring the question posed in the introduction of this thesis what is entrepreneurial motivation and how is it affected by change? Discussing the theoretical background and paradigmatic assumptions of the interpretative qualitative approach to research, and why it was chosen over a functionalist quantitative approach. Once the reasons for a qualitative approach have been presented I discuss the researcher's role in interpretative study. This discussion of interpretative study finally presents phenomenology and narrative approaches to research. Under which methods of data collection, research study design and analysis within these approaches, in order to provide the reader with an understanding of how data collection and analysis was conducted.

\section{The Functionalist Paradigm}

The majority of entrepreneurship research is still functionalist in nature, using questionnaires to generate understanding through comparing entrepreneurs to nonentrepreneurs across personality dimensions. The functionalist paradigm has been the primary paradigm for entrepreneurship study, operating on assumptions about the rationality of human actions and beliefs that one can understand human behaviour through hypothesis testing (Burrell \& Morgan, 2005). This is done in order to determine differences between individuals for the purposes of predicting potential entrepreneurial ability. Survey research may be able to provide generalizable data about surface level concepts, but it tends to fail in providing depth with the 'what, why, and how' of social phenomena like entrepreneurial motivation. Entrepreneurship research has been substantially focused on the use of questionnaires to test the concept. However the creativity, novelty and pioneering nature of entrepreneurship do not align well with the linear measurement of surveys and questionnaires (Bygrave, 1989). For these reasons I chose to adopt an interpretative approach to data collection and analysis.

\section{The Interpretative Paradigm}

The received view of functionalism has tackled the study of entrepreneurial motivation with quantitative methods. Arguing that types of motivation need to be separated and objectively analysed in order to make meaningful inferences (Vijaya \& Kamalanabhan, 1998). However there are alternative methods that can be useful in furthering our understanding of phenomena from an interpretative paradigm of generating knowledge. The limitations of the functionalist paradigm need to be 
supplemented with research in the form of exploratory and experience based approaches. The interpretative paradigm seeks to explain behaviour through individual lived experience. Interpretative researchers see reality construction as an ongoing process that can be understood through subjective interpretation of meaning (Guba \& Lincoln, 1994). This adds depth of understanding about how individuals experience and create meaning about the phenomenon of entrepreneurial motivation. Due to my interest in entrepreneurial motivation at the level of individual experience an interpretative approach has been taken.

\section{Paradigmatic Assumptions}

The assumptions of the interpretative paradigm need to be discussed in order to contextualize the nature of the research presented in the following findings and discussion chapters. I use aspects of phenomenological and narrative approaches towards data collection and analysis, grounded in an interpretative paradigm, in conducting this research. This paradigm has many assumptions which differ from the widely accepted functionalist received view. I see reality as a product of the mind rather than something that is external to the individual. This is because in order to truly understand something you must experience it, as reality is socially constructed through human interaction (Burrell \& Morgan, 2005). This is why I believe analysis of the written or spoken word provides a greater depth of understanding social phenomena than the analysis of numerical data. I explore the phenomena of interest from an interpretative paradigm as a result of my desire to gain understanding in to entrepreneurial motivation and change through the stories of lived experience that entrepreneurs describe about the phenomena.

\section{Researcher's Role}

My role as interpreter in this study has some very important implications in regards to both the research process, and the knowledge generated through that process. In interpretative accounts of a phenomenon the researcher brings prior knowledge of the phenomenon under investigation to the analysis of textual data. The feedback the interpreter receives whilst gathering and analysing the data promotes a new interpretation of the concept they are studying. Because of this each time the researcher interacts with respondents new understandings are being generated, which is why it is the researcher that must eventually decide that their interpretation is as close to reality as possible (Bowe \& Sloan, 2014). It is important in my role as interpreter that I recognise the influence of my bias in the process of collecting data and the process of generating knowledge from that data. 


\section{Bias}

In any interpretative study the role of bias and prejudice is an essential part to be taken account of. The interpretation of phenomena always involves some prior knowledge or understanding of those phenomena. This is why acknowledging my prior knowledge and understanding before engaging in data collection and analysis is so important. My preconceptions about the meaning of phenomena will have a direct influence on my interpretations of the meaning of those phenomena (Gadamer, 1975). My role as interpreter of experience plays an important part in the generation of knowledge in this interpretative phenomenological account. However it is still essential that these interpretations are true to the respondents accounts. Taking into account that my bias and prejudice are likely to be apparent in my interpretation is essential. Through remaining mindful of this I will keep true to the respondents account as closely as possible.

\section{Experience}

Interpretative approaches to understanding phenomena focus on the lived experience of multiple individuals. The reason multiple individuals are used is that I seek to understand the universal nature of lived experience, rather than any one individual's experience of a phenomenon. To a phenomenological researcher the universal nature of an experience is of central importance (Bowe \& Sloan, 2014). In this study I am interested in the shared experience of entrepreneurial motivation and its relationship with change. This research involves the attempt to understand the universal nature of these phenomena through identifying shared experiences of them. In order to understand the universal nature of a particular experience we gather descriptions from multiple individuals who have shared the same experience. Analysing the lived experiences of multiple individuals can be done through generating stories or narratives of individual experience (Guba \& Lincoln, 1994). My role is to interpret these narratives of individual lived experiences in reference to the greater phenomena of interest, rather than focusing on any individual account.

\section{Research Methods}

This section discusses the narrative and phenomenological approaches to data collection and analysis. It does this in reference to the salient aspects of each in this study. A narrative approach is useful in generating understanding about the phenomena of interest in the collection of data. The motivation to engage in entrepreneurial activity across changing contexts is understood through the stories they tell about themselves (Polkinghorne, 1988). Through the use of narrative to generate stories we can gain understanding and meaning rather than placing them on personality dimensions. Once these stories of lived experience have been 
collected an interpretative phenomenological approach to the collection of data may be taken. As a field of study phenomenology is a theoretical point of view asserting that the study of human experience allows us to understand human behaviour. It views experience as determining human behaviour rather than determining reality, which is external to the individual (Bowe \& Sloan, 2014). This point of view becomes a method when it is utilized to gather meaning through the analysis of individuals descriptions through written or spoken word. A phenomenological approach to data analysis involves multiple reading of the text, isolating themes pertaining to the phenomena under investigation, and interpreting the meaning of these themes (Moustakas, 1994). The following sections provide a discussion of these approaches in relation to data collection and analysis in this study.

\section{Narrative}

A narrative approach towards data collection involves the generation of stories from individuals who have experienced the phenomena of interest. The researcher is interested in the individual's story of the phenomenon, compared to a phenomenological account which is interested in understanding the overall phenomenon. Here I am interested in generating a better understanding of the phenomena through interpreting each respondent's story as a singular event, before relating these individual narratives back to the universal experience. My approach to data collection is to generate narratives of lived experience. Narrative has been defined broadly in the literature, revolving around the stories we tell that generate meaning, this meaning is produced in the interaction between the meaning maker and its recipient (Albrecht \& Surprenant, 2006). For it to be considered a narrative this meaning must contain space (a world, characters, objects), time (changes of state) and plot (causal relations, motivations) (Polkinghorne, 1988). I seek to interpret the meaning of these narratives through an interpretative phenomenological approach to data analysis.

\section{Phenomenology}

In my research I take an interpretative phenomenological approach to data analysis. There are two schools of phenomenology. The first is known as descriptive phenomenology established by Edmund Husserl, which was followed by interpretative phenomenology developed by Husserl's former research assistant Martin Heidegger (Bowe \& Sloan, 2014). Interpretative or hermeneutic phenomenology is focused on describing the meanings of lived experience, using reflection and writing to investigate a phenomenon. This is done in order to develop a description that provides understanding of the phenomenon itself (Osborne, 1994). As opposed to descriptive phenomenology, interpretative asserts that an individual's previous experience of the phenomena cannot be removed and remains a part of the interpretation. Interpretative phenomenology asserts that there is interpretation involved in all description. This is because perception of the reality of an object is dependent on a subject; the objects reality is dependent on its existence 
within the subject's consciousness (Moustakas, 1994). This is why in social sciences it is important to understand phenomena at the level of individual experience. Unlike functionalist perspectives of phenomena only an interpretative account can generate understanding and meaning about social phenomena that cannot be explained by cause and effect relationships (Laverty, 2003). My belief in the researcher's role as interpreter rather than describer drives my adoption of an interpretative phenomenological approach.

Phenomenological research requires the identification of a shared experience, aiming to understand the nature of that experience. The shared experience identified in this thesis is the relationship between entrepreneurial motivation and change. Interpretative phenomenology involves the interpretation of meaning at the level of individual lived experience. Through understanding the underlying dynamics of multiple lived experiences we may understand the shared nature of that experience (Moustakas, 1994). Phenomenology is not concerned with facts and redundancy, but rather with the meanings and significance created through shared lived experience. It identifies these meanings and understandings through examining multiple interpretations of lived experience. Multiple interpretations of an experience lead to a shared understanding of that experience, which brings us closer to a general understanding of the phenomena experienced. There is an attempt to identify the universal nature of experiences through understanding the shared experience of many individuals who are experiencing the same phenomena (Creswell, 2012). You have multiple people who have experienced the same thing which enables you to look back and make a general account of what that experience might be like. The interpretation would involve saying something like all of the respondents said $x$, and none of them said $y$, so possibly this is an important part of the experience (Gadamer, 1975).

\section{Data Collection}

Determining what an experience means in phenomenological research requires respondents that have lived the experience and are able to comprehensively describe it. Through collecting rich descriptions of individual lived experience gathered in interviews and interpreting their individual meanings, universal meanings may be extracted. This universal meaning is extracted through establishing an understanding of meaningful relationships implicit in descriptions of individual lived experience (Moustakas, 1994, P. 14). This section discusses how descriptions of experience were collected from respondents in a way that generated rich descriptions of lived experience.

In order to generate meaning and understanding about a phenomenon qualitative researchers seek out descriptive and interpretative accounts from individuals who have experienced that phenomenon (Guba \& Lincoln, 1994). The belief that 
knowledge can be derived from these accounts comes from the perspective that we construct reality through the beliefs, norms and attitudes developed through our experiences. It is through the stories of those experiences that we can generate the textual data required to develop some understanding of a phenomenon. Because of these beliefs I chose to conduct semi-structured interviews aimed at generating an organic narrative in order to engage in an interpretative analysis of the phenomena. These interviews were governed using an interview guide in order to focus and lead the interview towards the phenomena of interest. I used semi-structured interviews to collect descriptive accounts of entrepreneurial motivation from experienced entrepreneurs.

\section{Semi-structured Interviews}

It is useful to contrast semi-structured interviews with structured interviews. Semistructured interviews include an interview schedule with a set of questions, but unlike a structured interview, it is only guided by these questions not controlled by them (Gibson, 1998). The interests and concerns of the interviewer and interviewee are given more attention than would be given in a structured interview. The interviewer's role in a semi-structured interview is to influence and guide rather than dictate how the interview will proceed (Smith, Flowers, \& Larkin, 2009). As an inexperienced researcher a semi-structured interview will help me to remain on topics that tap the phenomena, where an unstructured interview may lead me to miss something. Semi-structured interviews also allow the interview process to remain organic in that I may still pursue avenues of interest, where structured interviews would prevent it.

Data collection was done through semi-structured interviews. Semi-structured interviews were chosen in order to allow a more organic dialogue between interviewer and interviewee. This allowed for questions to be modified and interesting avenues to be pursued more freely. A flexible approach is needed in generating understanding of individual lived experience of a phenomenon (Gibson, 1998). Because I'm interested in the respondents experience allowing them to talk freely prevents my presuppositions becoming imposed on the interpretation of that experience. The use of semi-structured interviews aims to generate understanding through the narrators stories without "offering interpretations, judgments or otherwise imposing the interviewer's own relevancies" (Hollway \& Jefferson, 2000, P. 36). The interviewers own interpretations should only come through in the dialogue for assurance that interpretations of the interviewee's narratives are as close to their lived experience as possible. The interviews will be semi-structured in 
order to provide some direction towards the research question, whilst keeping this direction somewhat organic.

\section{Data Collection Process}

The data collection process took place over one month; this included the travel necessary to meet two respondents in Auckland and two in Tauranga. Interviews were recorded on a media recording device. These recordings were then transcribed verbatim. Once data had been collected and transcribed it was analysed using interpretative phenomenological analysis. Each transcript was first read over whilst making comments, without offering any interpretation of meaning. In the second reading of the transcript comments were converted in to themes, which were listed on a document for each transcript. The next stage of analysis involved going through each table of themes and ordering them theoretically. After this each table of themes was combined in to a master table of themes. This table included sub themes and identifiers so that the importance of each theme could be traced back to the description in the transcript. The collection process generated narratives of lived experience, whilst the analysis generated themes from those narratives. The meaning of these themes will be interpreted and discussed in chapter 5 .

\section{Research Study Design}

This section describes how my study was designed. It discusses how relevant respondents were identified and contacted as well as the way in which the interview was structured and conducted. It aims to further ground the methods used in order to support the validity of the following results and discussion chapters. This will give the reader a more thorough understanding of how the research process led to the conclusions drawn about the relationship between entrepreneurial motivation and change.

\section{Recruitment}

Purposive sampling was chosen due to the necessity of obtaining information from a specific target group. In purposive sampling individuals who fit a certain criteria set by the researcher are chosen (Cavana, Delahaye, \& Sekaran, 2001). One type of purposive sampling is snowball sampling. It was chosen as the most efficient way to obtain access to respondents for various reasons. Entrepreneurs have very specific characteristics as defined by this thesis and possess the knowledge needed to provide insight. The problem was that these individuals are very difficult to locate and contact. Because of this problem of accessibility snowball sampling was the most efficient and suitable method of sampling for this study. 
The first individual was selected based on the specific criteria set in this thesis. New subjects were then selected based on information and recommendation provided by the initial subject through snowball sampling. Respondents were contacted via email. I obtained the information of these individuals through family, friends, and acquaintances of mine. Through getting respondents to contact other entrepreneurs who may be interested I ended my recruitment phase with a sample size of seven. Snowball sampling allowed me to obtain access to respondents who fit the criteria set by this thesis.

\section{Ethics}

It is essential in all research studies to address ethical issues affecting those who collect the data and those who provide it (Cavana, Delahaye, \& Sekaran, 2001). As the researcher it was essential that I protected the confidentiality of my respondents. This was achieved through the use of pseudonyms in quoting the transcripts as well as destroying the data after 12 months. Interview transcripts are being kept on a computer protected by a password. Secondly I established what the purpose of my research was before conducting the interviews, including the use of participant consent forms. The self-esteem and self-respect of my respondents was taken in to consideration at all times during the interview process and their right to choose what they wished to discuss was respected. Addressing ethical issues in the collection and presentation of data should lead to ethically conducted research. I was granted ethics approval by the Human Ethics Committee (HEC) at Victoria University of Wellington, which recognised that I had sufficiently addressed ethical issues.

Informed Consent was obtained through providing respondents with a consent form outlining the aims and objectives of my research, disclosing the direction that interviews would likely take (see appendix a). This consent ensured respondents autonomy, privacy, and confidentiality. All relevant research information was given in order to ensure that respondents had autonomy, letting them know that they may refuse to answer any questions and end the interview at any time. Privacy refers to people's interest in controlling the access of others to themselves. The importance of privacy led me to the conclusion that respondents should not be forced to give access to personal information at any point. Confidentiality is related to privacy in that it is about identifiable data and how the participant wants data provided by them to be related back to them (Cooper \& Hartnett, 2010). Measures to respect respondent's autonomy, privacy, and confidentiality were ensured before data was collected. 


\section{Sample}

In qualitative research it is essential to provide a description of the research process in order to establish understanding of the sources and meaning of its themes (Cavana, Delahaye, \& Sekaran, 2001). What parameters were set with regards to respondents are important to consider. This will give the reader a better understanding of who the individuals involved in this study are. Who these individuals are is important because this study is generating understanding from their experiences. How these individuals were chosen is also important to consider in giving the reader an idea of how accurately the sample size represents the target population. All of this information is provided in order to give the reader an accurate idea of the research sample and interview process.

When determining this study's parameters it was important to take in to account the size and scope of this study. Phenomenological studies usually consist of a small number of respondents, with a homogenous range of individuals (Moustakas, 1994). The first parameter I set was that individuals must be experienced in business and entrepreneurship. This is an important parameter because in order to discuss their experience of change they must have a broad enough experience of it. In the context of this study I consider an individual experienced if they have ran their own business for at least 3 years and be over the age of 30. This is because in order to generate understanding about the relationship between entrepreneurial motivations and change my respondents must have experienced enough change to describe it in depth. The second parameter I set around my study was that a sample size of 6-10 was required. This sample size was chosen in order to have enough respondents to provide the requisite data to draw some understanding about the phenomena whilst taking in to account financial and time limits. Once the parameters around my study were set it would need to be determined how respondents would be contacted and identified.

The parameters around the scope and size of my study did not overly determine the demographic makeup of my final sample. However the difficulty in contacting respondents led to a largely homogenous background. My sample size consisted of seven white males between 46 and 70. Three of these individuals operate out of Auckland, two in Wellington, and two in Tauranga. In terms of their respective industries two were in the finance sector, two were in the forestry sector, one was in engineering, one was in information technology and one respondent was the CEO of a large retail operation. These access issues led to a relatively homogenous sample. 


\section{Interview process}

The identification of respondents was followed by the choice of interview process. How these interviews were conducted is also important to consider. This will give a greater understanding of how textual data was generated. In the beginning I entered the interviews without a planned sequence of questions in order to allow issues to surface organically. This allowed me to decide which themes required further probing. The interview process consisted of broad questions being asked around topics surrounding motivation and change. I then managed the direction of responses to these questions through summarising, paraphrasing and probing. The interviews were all conducted face-to-face in the offices or homes of respondents. The only exception to this was an interview that was conducted over skype. The audio of each interview was recorded on a media recording device and transcribed verbatim following these interviews. The average length of each interview was 38 minutes. All seven interviews were conducted in a similar manner.

The semi-structured interviews that I conducted began as unstructured interviews with an open ended question such as "What has your experience of entrepreneurial motivation been?" I then managed the response through probing and elaborating to elicit further information. Once the information drawn from that question dried up I switched to the next pre-planned question on the list (see appendix b). The topics chosen for the pre-planned questions were based on the extant literature on entrepreneurial motivation and change. As the data collection process progressed this topic guide was altered when respondents attached importance to concepts which were previously left out. This led me to modify the interview guide in response to new avenues of interest that allowed me to generate understanding in relation to the research question.

\section{Data Analysis}

Now that important concepts in interpretative phenomenology have been discussed the specific process I used to interpret data will be presented. In interpretative phenomenological analysis (IPA) we are interested in the significance and complexity of the meanings taken from the interview rather than the frequency of each meaning (Smith, Flowers, \& Larkin, 2009). This method follows an idiographic approach to analysis. In interpretative phenomenological studies which use a large number of respondents it is often better to look in-depth at one interview before moving to the next in order to increasingly discover the significance and complexity within each descriptions meaning. The main aim of an IPA researcher is to reach some understanding of what it is like to be in the respondents shoes (Pietkiewicz \& 
Smith, 2014). The following sections present the hermeneutic circle as a way of describing the process of interpretation and the stages of IPA that were undertaken in the analysis of respondents lived experience.

\section{Hermeneutic Circle}

Hermeneutics is a way of analysing and interpreting data. The hermeneutic circle is a process or condition of understanding the data in a manuscript from the top down and bottom up, "coming to understand the meaning of the whole of a text and coming to understand its parts were always interdependent activities" (Schwandt, 2007, P. 133). The argument behind this method is that in order to understand the whole you must understand its parts, however in order to understand a part of the whole there must be some understanding of the wholes context. Through this understanding of the whole and its parts I will be engaging in the interpretation of phenomena from an interpretative phenomenological approach. This approach aims to come to understand the meaning of textual data. The hermeneutic circle best illustrates the process of reading and re-reading the parts in order to understand the whole. In this study the transcripts were treated in this manner in order to get as close to a full understanding as possible. With each transcript interpreted individually before combining these interpretations to provide a general understanding of the whole.

The hermeneutic circle is an important concept to understand in the process of analysing data from an interpretative phenomenological approach. The rationale for this approach to interpretation is that an individual's interpretation of a concept changes in different contexts; seeing things one way at a certain point, and then another way at a different point. At some stage however, through using this circular process of understanding, the researcher must come to a decision that he or she has a complete or correct understanding of the text. Although we are bound to continually interpret a piece of text according to the contexts we have experienced differently across time, there must come a point where the text has been analysed to a satisfactory degree (Gadamer, 1975). The hermeneutic circle is an important concept to understand in the process of analysing data from an interpretative phenomenological approach. The process of reading, and re-reading was undertaken in this study in an effort to come as close to a complete understand of respondents lived experience as possible.

\section{Steps of Interpretative Phenomenological Analysis}

There are multiple steps in Interpretative Phenomenological Analysis (IPA). The transcript is first read through looking for interesting insights without any rules 
about what is to be commented on. The second reading is done in an attempt to generate theme titles from previous comments. The entire transcript is treated as data at this point and no attempt is made to submit or omit any particular section for special attention. The emergent themes are listed on a piece of paper and you look for connections between them. First the themes are organized in chronological order and then theoretical ordering as more connections between themes are made. The primary transcripts are checked in order to ensure the connections between themes make sense once they have been listed. The next stage is to produce a table of themes ordered coherently, with clusters of themes given a higher order name; each theme is given page numbers and key words to act as identifiers (Smith, Flowers, \& Larkin, 2009).

These steps are illustrated in the following example. When reading through one respondents transcript the first time he mentioned "they restructured and changed a lot of the directors, and I couldn't live with their constrained thinking... the opportunity to leave and start my own company came". This description of the respondent feeling as though he had to leave that company and start his own business led to the comment of 'circumstances made him feel as though he had to leave'. The second reading led to the theme 'external circumstances pushed him in to entrepreneurship'. After multiple readings of all seven transcripts, the themes from each were grouped under higher order themes, as clusters of meaning. The theme taken under this transcript ended up being placed under "External environment creates entrepreneurial trajectory". This is the process that each transcript underwent leading to the creation of a master table of themes (see appendix C).

The final table of themes for each interview includes the higher order theme for each cluster, the subthemes, and identifiers in the form of page numbers and key words to support the theme. This transcript is then put aside and the same process is undertaken for the subsequent participant. As each transcript is analysed it is also important to recognize both convergence and divergence in the emerging themes. A master table (see appendix c) is created for all themes and transcripts with identifiers showing their prevalence and richness. In the writing up phase analysis is continued as the themes are transformed in to each participant's narrative account. The themes apparent in each narrative are then explained, illustrated and nuanced. This takes the form of a narrative argument with added verbatim from the transcripts to support the themes. 
Presentation of Findings and Discussion

Care must be taken to distinguish clearly what the respondent said and the researcher's interpretation of it (Bowe \& Sloan, 2014). I did this first by clarifying what the respondent meant during the interview and then once I presented the data I explicitly stated which parts were the respondent's descriptions and which parts were my interpretation. The results section in chapter 5 contains the presentation and description of narratives and themes from those narratives. Following that chapter 6 links that analysis to the extant literature, and offers my interpretation of what those themes mean for what entrepreneurial motivation is and how it is affected by change. 


\section{Chapter 4: Findings}

\section{Introduction}

This chapter presents the findings of my study. These findings relate to the purpose of exploring entrepreneurial motivation and change. This chapter first introduces each respondent's narrative, in order to provide a greater understanding of their lived experience. Then presenting the major themes found in those narratives of lived experience, it compares and contrasts how those themes were described by respondents. This is done without interpreting the data collected. Chapter 4 presents the findings of this study, which are then discussed and interpreted in relation to the literature and research question in chapter 5.

\section{Respondent Demographics}

The demographic makeup of my respondents was largely homogenous. This was due to the difficulty in gaining access to entrepreneurs, especially those willing and able to take part in this study. I interviewed seven respondents, all of whom were white males between the age of 46 and 70 . Each entrepreneur had been operating in New Zealand for the greater part of their career, which meant they had enough experience of change to relate to the purpose of this study. The most diverse aspect of my respondents was that they all came from different industries. This enabled me to focus on their entrepreneurial acumen rather than a specific sector of business. The study involved two entrepreneurs from the finance sector, two from the forestry sector, one from the retail sector, one from the IT sector, and one operating in the engineering/technology sector. In order to interview each respondent I had to travel too Tauranga, Auckland, and Wellington. This section introduces each respondent's narrative briefly. This is done in order to give the reader a better understanding of each individual's story. Providing a context for how the themes of External Environment, Upbringing, Drive, Experience, Adaptation, Risk, and Passion emerged in the section following. Respondents are introduced in chronological order using pseudonyms before the themes generated from their narratives are presented in the following section.

Jack

Jack is an entrepreneur involved in importing and exporting logs internationally. Throughout his life he worked in the forest service in many different positions, working his way up in a large New Zealand company. This all led to being made redundant after 22 years. Once being made redundant he searched for a new job, however the opportunity came to load a ship and he took it, being made "redundant led me into entrepreneurship" but he was mainly motivated by "my ambition to 
make more money". When describing his experience of change he related "in me? What's changed the most, I think age".

\section{Parker}

Parker was another veteran of the forestry industry. He held multiple positions in many industries, before working his way up the corporate ladder of a New Zealand forestry company. When the company restructured he "couldn't live with their constrained thinking... the opportunity came to leave and start my own company when people came to me and suggested it". His experience of motivation was "mainly a desire to do well" but like Jack he was pushed in to entrepreneurship through redundancy. His experience of change was that "it didn't change much... the change in running a business day to day excited me and drove me forward".

\section{Norman}

Norman also had multiple jobs from an early age beginning with "delivering groceries... cleaning sewers... working in civil aviation". In contrast to the others however, there was no business related influence in his upbringing. And rather than being forced in to entrepreneurship he decided to do it, and desired to do it, because he desired independence. Describing a need to achieve things and a love for engineering, he eventually started an engineering company. When reflecting on changes effects on his motivation Norman said "I think change spurs you on... brings new challenges... I like to embrace change".

\section{Samuel}

Samuel is the CEO and founder of a major New Zealand retail company. He grew up watching his parents working very hard, which led him do the same throughout university. Once it became clear that he was going to be made redundant he took the leap of starting his own company, something that "I always had in the back of my mind... I thought it would be a great idea to be an entrepreneur". In terms of motivation he expressed that "I've been quite internally driven... I get a lot of satisfaction out of successes". He described that "I think things have stayed relatively the same... time goes by but the drive stays the same".

\section{Wallace}

Wallace held multiple positions across the finance industry throughout his career. His attitude towards work was not so strong until he had an epiphany in university. From there he became very studious, reaching the top of his school. After years working in various positions in the finance sector he took the risk of investing in a small start-up company, and from there went on to become very successful. He 
describes his experience of change in a similar way to the others "I've kind of changed it myself as it's gone through... after the epiphany nothing has changed since then...things do change, nothing stays the same forever".

\section{Patrick}

The other respondent who operated in the finance industry was Patrick. His father instilled in him a love for business and throughout his studies he knew what he wanted to do. His experience of change was that "it is constant and look it's just something you absolutely have to accept... and you have to always look at it as being an opportunity... this whole thing happens very quickly, sitting in your chair one day and mine the next".

\section{Rick}

Rick had a very long and storied career in New Zealand's public sector before deciding to set up his own company. He always wanted to be an entrepreneur, his family were all entrepreneurs and he felt that it was an important part of what made him who he is. Finally the opportunity appeared to start his own IT company and it was the area he was most passionate about so Rick dove in to that opportunity and hasn't looked back. He described his drive to do things as "definitely internal! The thing that is driving me is what I want to see... good things happen". His experience of change was that "it's a natural part of your life; you've just got to adapt to change... I'm a different person than I was 5 years ago but I'm also the same person".

\section{Overview of Themes}

Each narrative provided by the respondent's was unique in terms of individual lived experience. In this study the narratives contain themes that were found through interpretative phenomenological analysis to be meaningful within the context of the greater phenomena. These themes interrelate in a way that provides some understanding of the relationship between entrepreneurial motivation and change. This section presents these themes with reference to each narrative, comparing and contrasting each respondent's experience of the theme. The purpose of this thesis was to further develop understanding of the relationship between entrepreneurial motivation and change, asking what is entrepreneurial motivation and how is it affected by change. The themes that emerged from the narratives were organised on a master table of themes (see appendix c). These themes shed some light on the research question of this thesis and are presented in order of their emergence, with quotations being used to compare and contrast the experience that each respondent had of the theme. 
These seven themes provide insight in to what entrepreneurial motivation is, and how it is affected by change. It is clear that the internal drive to achieve things is constant for most of these individuals. This drive to achieve things is not always directed towards entrepreneurship. However all respondents experienced that the external environment creates an entrepreneurial trajectory, directing this drive towards entrepreneurship. This drive to achieve things and the role of passion in entrepreneurship seems to be instilled in them through the influence of upbringing in entrepreneurial motivation. The risk involved in the decision to engage in entrepreneurship seems to be decreased for them, because experience builds selfefficacy which leads to decreased ambiguity and risk. This increased tolerance for risk seems to be confounded by an attitude that there is risk and ambiguity in both corporate and entrepreneurial roles.

All of these aspects of entrepreneurial motivation seem to come together in the entrepreneur's reaction to change, as was described by using sailing as a metaphor for adaptation in entrepreneurial motivation and change. The entrepreneur has an internal drive and passion towards achievement. Change is constant, and in order to achieve whatever this constant internal drive and passion is directing them towards, they must adapt to these external changes. The following section discusses these findings from the analysis in relation to the literature, the research questions and the conclusion of this thesis.

\section{External Environment}

Respondents were asked to describe the experiences in life that led to their entrepreneurial decision. All recalled an event in their life that sparked their motivation to start their own business. Whether they were comfortable with corporate life or already had thoughts about engaging in entrepreneurship, there was always an event in their life that sparked their entrepreneurial motivation. This external event always led them to exploit an opportunity, whether that opportunity was sought out or came to them through necessity (Shapero \& Sokol, 1982).

For Jack and Parker an external event pushed them in to entrepreneurship. This external event first disrupted their corporate lives as Jack described "It was a good job... the company underwent restructuring... it was what do you do after 22 years when I was made redundant... it was a good job and I didn't see anything outside of that job, until it was forced upon me". Parker had a similar experience of disruption when "they restructured and changed a lot of the directors and I couldn't live within their constrained thinking". After disrupting their corporate lives the external environment provided them with an opportunity to take advantage of this 
disruption. This was clear in jack's description where "a couple of months later I was lucky... an opportunity came up to load a ship". Parker had a similar event occur in the external environment when "the opportunity to leave and start my own company came, when people in the industry came to me and suggested it". Jack and Parker were not searching for entrepreneurship; it was forced upon them by external events.

These experiences are in contrast to Norman and Samuel for whom the idea of becoming an entrepreneur was always in the back of their mind, they just needed the leverage to engage in it. This desire was expressed by Norman who described how "I was talking to a friend, and we had quite a long liquid lunch, and we were talking about why we didn't seem to be rich, and we worked out that it was because we were working for somebody else... so this was on a Friday and literally on the Monday I went to a lawyer and said I would like to start a company...I had been thinking about it for the previous 2 or 3 years... so I thought hey that's for me". Like Norman, Samuel had in the back of his mind the idea of entrepreneurship but the comfort of corporate life did not provide him with the leverage to do so in the beginning. Samuel expressed how "I always had in the back of my mind it would be a great idea to run my own business and be my own boss, but I wasn't in any hurry to do that... I was kind of forced in to it towards the end when the company I worked for was about to be taken over". Like Norman, Samuel just needed the leverage to engage in his desire to start his own company.

For Rick the idea of entrepreneurship was instilled in his upbringing, he just needed the external environment to provide him with the right opportunity. He recalled that "I ended up in corporate life because ya know family you've got to feed them...I enjoyed my jobs but deep down the passion was there to do my own thing... and I think I mentioned my families background is running their own businesses... basically I was happy doing what I was doing but secretly I was saying what I was going to go and do... and once I found the right idea I started working on that idea". These respondents all described an external event providing them with an opportunity to take an entrepreneurial trajectory, whether they desired that opportunity or not.

\section{Upbringing}

The influence of the respondent's family and upbringing on their entrepreneurial motivation was a recurring theme described in their experiences. The influence of upbringing on entrepreneurial potential is quite apparent in the values and beliefs instilled in individuals from a young age (Caspi \& Roberts, 2001). These values and 
beliefs influence their behavior towards opportunities that surface later in life. The behavior that seems most apparent is an intense work ethic and belief in getting done what needs to be done, in order to achieve what you want to achieve. It is clear in all respondent's narratives of lived experience that upbringing instilled in these individual's important values and beliefs in relation to their entrepreneurial motivation.

Respondent's did not necessarily grow up in a business environment, but still learnt important values and beliefs. Parker was brought up on a farm where he learnt values and attitudes that have guided his behavior throughout life. He described that "my family was hard workers... our family had an ethos of hard work and commitment... we didn't have all of the luxuries of life... I always felt it would take more than a regular salary to provide what I wanted for my family". When asked about his attitude towards work he described it as being "making as much money as possible to provide a better life for my family". This is similar to Norman who was not brought up in a business environment, but still learnt important values and attitudes for a business environment.

Norman described that "it's interesting to look back because my mother had no education to speak of... my father had no high school education, so there was no family environment for business or entrepreneurship, but I certainly was encouraged to do the best that I could do in whatever discipline... my father was always encouraging me to be independent and self-sufficient... he was always encouraging me to be able to stand on my own two feet from a very, very young age". Samuel wasn't brought up in an entrepreneurial environment also, but "I think [my drive] was mainly driven by watching my parents... they were very hard workers... so I saw them toiling away when I was coming home from school... they put a huge amount of work in to doing that to pass on the benefits to my family... so I think that the way they led by example affected me the most... I admired what my parents had done and thought if I did as well as they had, working hard and achieving what they had".

Patrick and Rick were brought up with business as an important part of their family's lives which instilled in them a passion for it. This was described by Patrick who when asked why do you love business responded "Probably family I think... from a young age my dad was a general manager of various businesses so he'd always be discussing business and how it worked and made it always seem interesting and exciting so it just sort of carried on and I guess without business I don't know what I'd do with myself". This experience is similar to Rick's, who 
described that "I think I mentioned my families background is running their own businesses, my brother and father ran their own businesses, and that was the way we operated... I was happy doing what I was doing but secretly I was saying what I was going to go and do".

Whether they were brought up in a business environment or not, it is clear that their upbringing instilled in them important values, norms and attitudes that led to their entrepreneurial motivation later in life. The most influential of which seem to be a passion for hard work and an intense internal drive to achieve leading to a strong work ethic. The respondent's upbringing clearly had an important role in their entrepreneurial motivation and attitudes towards change.

\section{Drive}

A theme that appeared in every respondents experience was an internal drive to achieve things. When asked about their experience of entrepreneurial motivation in relation to change all respondents described an internal drive that remained constant. This internal drive was directed at external goals, such as making money or providing for their family. They all expressed in some way or another that internal drive stayed the same across time whilst external goals changed.

Jack described being driven by some internal ambition "yes, it was being made redundant but also my ambition". This mind-set of "making money, and as much as possible... was always consistent". Parker also had an internal drive to achieve things which led him to develop his capabilities, his success was "because of my own effort and achievement and enthusiasm and commitment... I worked longer hours than most people, I went on courses, and I was committed to doing well... I know that in order to achieve what I want to achieve I have to hit certain standards... it's the need to hit those standards that drives me".

This was similar to Norman who described being "motivated and energetic... I've always felt motivated to do stuff and I can't imagine not being motivated... almost drawing from the changes happening to use as my energy... I hope the drive will always be there... external things change with time, and the internal things are the engine room as it were, with the energy from that engine room being channeled in several directions... external things change whilst internal things remain the same". Norman felt that his motivation will never go away.

This experience is similar to Samuel's, who was always "quite internally driven... that's what gets me up every day, I really love that, so I imagine that I will keep doing these sorts of things until I peg". Samuel described how he "was always 
interested in work... I was fascinated by it and ambitious to get on, I wanted to make a success out of my life and I thought that the way to get there was by working hard and becoming immersed in my job, and I would succeed in doing that". When asked about whether this motivation was internal or external he described it as "A bit of both... I think I've been quite internally driven, but I think I've also been quite competitive... I like to succeed, seeing yourself succeed externally is also kind of a motivator... progress is definitely a motivator".

Wallace described experiencing a strong sense of satisfaction out of achievement "it gave me a big thrill to see what comes out of working hard and applying yourself... I must have unlocked an internal drive... as soon as it happened I wanted to become the top of everything... I used to go in to exams at university and look at people and go 'I know I'm going to get a better mark than you'... I didn't want to be ordinary; I wanted to do really well". Whilst for Rick passion fuelled his internal motivation, "very positive, very energetic... if you had a job to do, you get it done... running your own company is like commanding your destiny". Rick described how his desire to do what he was passionate about led to a drive that was "definitely internal! There's a little bit of external as well, the feeling I get from positive feedback is good... but the thing that is driving me is what I want to see, the satisfaction of building something".

This internal drive to achieve things was described as always being there, and seems to be what gave these entrepreneurs the energy and desire needed to engage in entrepreneurship. The drive to achieve things doesn't change internally, but rather the external goals that it is focused towards change the most (Getley, 1979). The internal drive to achieve things seems to be an important characteristic of entrepreneurial motivation.

\section{Experience}

One thing that seems to be affected by change in relation to entrepreneurial motivation is the entrepreneur's sense of self-efficacy. Respondents described that as their experience increased they believed more in their ability to achieve things. As change moves forward belief in the capabilities we have in the areas that we focus on increases. This enhanced self-efficacy with regards to certain areas leads to decreased ambiguity and risk in those areas, which allows these individuals to engage in entrepreneurship despite the risks involved (Budner, 1962).

Jack felt that his experience at his corporate job made him just as capable at running his own business. This was clear in how he described "when I started a company it 
was pretty much the same thing as in [corporate job], without having to justify everything I did... I was making a lot more decisions myself". This sense of selfefficacy made him comfortable dealing with the ambiguity involved in entrepreneurship "It really slotted in quite nicely actually... I was quite comfortable in what I was doing because of my background at [corporate]... it just progressed from a big company to my own... when you start your own business you realise everyone is equal".

Parker had 20 years of experience in his industry. This experience gave him a strong sense of self-efficacy in starting a new business. Parker described how "I took considerable risks with several different companies, and most of them failed, but the log exporting business didn't... and that's the business I knew the most about, in fact I don't think I'd be exaggerating if I said I was the most experienced person in NZ at the time... managing that type of business was my strength for 20 years, so I had a good opportunity to take advantage of that... I knew I wasn't going in blind". When describing the effects of change he related "my belief in my skills definitely grew... I was prepared to take the risk of leaving because I had the confidence in myself... you need a lot of drive to keep yourself going". It seems as though he found this development of skill to be essential, describing that "it's key to have built up the amount of value and experience to take advantage of an opportunity successfully... the opportunity came at the right place in my career when I had the ability to carry it out successfully".

Norman's experience reinforces that of Parker's, he found that "when you achieve something the next time around it's easier... it doesn't seem hard anymore, but to others it seems hard". Rick also experienced that increased skill through experience builds self-efficacy, describing how "I feel more prepared to do what I'm doing than someone who's in their 20s, just getting in to it... I feel that I've got a level of maturity with understanding how business works... I know that when I left school I came out with a very positive attitude and a strong belief in my capabilities".

Samuel described how this achievement in his area of expertise "gave me the belief in my abilities to be successful". When we discussed his attitudes towards risk he described that "I haven't been very risk averse... I had 12 years of experience learning to be a good retailer; I felt I had enough experience under the belt to back myself". Luckily at that point he had developed the necessary competences "it gave me the belief in my abilities to be successful and decreased the risks involved". However at the same time risk is increased because "as change goes forward you have less energy and enthusiasm". Patrick had a similar experience of increased skill 
in dealing with risk, and decreased energy and enthusiasm. He explained to me that "your skill set, because you're so much more experienced, really increases a lot and you have more skill in dealing with risk". He described that change can decrease your ability to tolerate risk even as experience goes up because as you age your responsibilities grow and energy levels diminish "two things happen, one: your skill-set really increases a lot, because you are so experienced and have seen most of the problems before... you have a lot more skill in dealing with risk but at the same time your appetite for risk is diminished... because of age and diminishing energy levels".

It is clear that as these individuals became more experienced in their respective industries they felt more confident in their ability to get things done. This increased belief in their ability to achieve desired results led to a decrease in any negative perception of ambiguity and risk, because with increased knowledge of something there is decreased ambiguity and risk involved with that thing (Atkinson, 1957). So in being experienced in their areas of expertise they felt less at risk of failure once the opportunity to engage in entrepreneurship emerged, which made them more willing to exploit that opportunity.

\section{Adaptation}

When discussing my respondent's experience of change and entrepreneurial motivation there was a recurrent theme of the need to adapt to changing circumstances. This theme was described as the attitude that when you have an internal drive to reach a certain point the only way you can deal with change effectively is to adapt to it. Two of the respondents used sailing as a metaphor to describe this theme. Respondents described their internal drive to get somewhere remaining constant, whilst having to adapt to external circumstances.

When asked about having to adapt his motivation to changing circumstances Norman related that "I've heard some people describe it a bit like sailing where there's a goal or a point you want to reach, in the yacht, and you can't change the direction of the wind, but you can change the direction of the sails, so that's quite a good way to describe the entrepreneurial journey". Norman describes his experiences and attitudes towards uncertainty from the view that "the whole of living is uncertain; either of us could be wiped out crossing the road... I think if your outlook is one of being adventurous then the world is a great place, some find it scary and some find it a wonderful place to be". In terms of change he stated that "I think change spurs you on and gives you a reason to do things... it brings new challenges, and is beneficial... I like to embrace change... I adapt very easily... I've 
always felt motivated and energetic... almost drawing energy from the changes happening around me". Uncertainty and change are constants, but in order to reach the point that his motivation is driving him towards he must adapt.

Wallace described the relationship between entrepreneurial motivation and change in a similar way. He narrated how "it's like on a boat right, if you're sailing from here to there and the wind changes direction you've still gotta get too there, you're still on the water so your goal is the same it's just that the conditions have changed, you've kinda gotta sail that way rather than the other way, you have that drive to get there but you might just have to take a slightly different course". We discussed his experience of change in relation to this, to which he responded that "internal drive stays the same... [Once you get money] you just carry on, I wanted to do good things... something different... I have my views set on certain areas and will continue to succeed in those areas".

Wallace described his attitude towards the risk inherent in change as being "something saying it's probably going to work out alright, and it usually does... I've learnt from taking on risk and managing it in whatever I do... what drives me now is seeing good things happen". In terms of his ability to affect change "I've kind of changed it myself as it's gone through; it hasn't been changed upon me, I've always looked for change myself... nothing has changed since the epiphany...having more money does change you... I suppose the only way I've changed since the epiphany is that you work hard and you get good at something and it can be gainful...things do change so you've just got to roll with it". Again the pattern of having an internal desire to achieve things, and adapting to change and ambiguity in order to attain those desired things is apparent in Warren's narrative.

The other respondents all described the same theme in different ways. Patrick related that his experience of change was that "it is constant, and look it's just something you absolutely have to accept because it's just going to happen the whole time, and you just have to look and see how you can profit from it... you always have to look at it in terms of being an opportunity". In terms of change to him "your knowledge base and experience goes up as change goes on but at the same time your energy and enthusiasm diminish". Samuel described his experience of change across his life, reflecting that "I think things stay relatively the same... time goes by but the drive stays the same... you've got to change the way you think as the external things change... there is always external change that you've got to adapt to". When discussing his experience of the relationship between motivation and change Parker said "I don't think my motivation changed that much, I still do the business in order 
to improve mine and my family's lives... I know that in order to achieve what I want to achieve for my family I have to hit certain standards... it's the need to hit those standards that drives me".

These experiences build upon the theme of inner drive remaining constant over time. The entrepreneurial motivation is the yacht and the ocean is the external environment, in order for the yacht to reach its goal it must adapt to the changing external environment as changes happens in the external environment, whilst the individual is motivated to reach a desired point, they must adapt in order to continue in the direction of that point. That is what makes the metaphor of sailing a well suited way of describing the role of adaptation in the relationship between entrepreneurial motivation and change. Whether this adaption is successful depends greatly on the individual's internal and external adaptability (Caspi \& Roberts, 2001).

\section{Risk}

A theme that constantly appeared amongst the respondents descriptions of their entrepreneurial experience was their attitude towards risk. They did not necessarily view themselves as taking more risks in their entrepreneurial role than their corporate one. There was an attitude that there is risk involved in all of business and life in general. The reason they did not feel much different going from a corporate role to an entrepreneurial role was due to self-efficacy decreasing perception of risk. This attitude came from a view that risk was pervasive across life.

This theme was most prominent in Patrick and Ricks descriptions. Patrick reflected that "certainly starting these businesses is risky and stressful...there is a lot of responsibility because you're feeding a number of mouths within the organisation... in the finance industry you're always under the stress of whether your performance is good enough... the nature of business is that it's risky, it's very competitive". He described his experience of stress and risk in both corporate and entrepreneurial roles "The gap between working in corporates and working for your self has really opened up... There are levels of stress and risk in bureaucratic and entrepreneurial organisations, just different kinds". Rick reflected the same experience in his description, asserting "Look you've never got control of everything, and there's ambiguity in the corporate world as well, you've just got to accept that [risk] and carry on".

It seems as though this belief that risk is pervasive comes from both upbringing and experience in business. Their high sense of self-efficacy developed through 
experience also seems to play an important part in giving them a high tolerance for risk, and an internal locus of control opportunity (Atkinson, 1957). Their belief that risk is a constant in life contributes to their decision to engage in entrepreneurship (Caliendo, Fossen, \& Kritikos, 2011). Through not viewing risk as avoidable they allow themselves to engage in endeavors that many others would see as the more risky route.

\section{Passion}

All respondents reflected the experience of passion towards business, entrepreneurship, or their particular discipline, as being a powerful motivator throughout their career. All respondent's experienced passion in different ways. Their descriptions all involve passion giving them the energy and enthusiasm to engage in their entrepreneurial role across change.

Jack described that above anything else passion towards work "never changed... It was passion... making money was on top of it but at the same time I just enjoyed doing the work". When the discussion with Parker turned to passion for his work he described that "I became quite passionate about it, which was reflected in my work ethic... this passion led me to work longer hours than what was the usual in this career... I loved it so was driven to success in it". Norman became passionate about his area of expertise, expressing that "I have a passion for engineering... it's the fulfilment of doing the work and having the ability to do things". Rick had a passion for entrepreneurship reflecting back on how "I enjoyed my jobs but deep down the passion was there to do my own thing... running your own business is like commanding your own destiny".

Patrick had a love for business from a young age expressing how "I've always sort of loved business from a young age, I always wanted to do well". We moved on to describing the nature of entrepreneurial motivation, which led him to describe that "there is a competitive nature to entrepreneurial personalities, so they're competitive... I really enjoyed business; I think if you didn't genuinely enjoy business you'd just be no good at it because everyone could tell you've got no passion for what you're doing". He related this passion to experiences during his upbringing when asked, what brought about your love for business? Patrick responded "probably family I think... from a young age my dad would always be discussing business... I guess without business I don't know what I'd do with myself". 
As with other respondents Rick described this passion as being instilled during his upbringing "I think I mentioned my family's background is running their own businesses". He intensely described his desire to engage in entrepreneurship reflecting how "I was happy doing what I was doing, but secretly I was saying once I found the right idea I was gone". When questioned about this desire to start a business he again described an experience of passion "why? Well you know life is short, you want to do something in an area you are passionate about... I enjoyed my jobs but deep down the passion was there to do my own thing". He described a belief that the fulfilment of his own values could only be fully complete through entrepreneurship "I'm not saying that other jobs weren't fulfilling but this is more fulfilling". When we discussed his experience of being an entrepreneur, and his attitudes towards the risks involved, he expressed that being an entrepreneur "more excites me than scares me... you know there's that old cliché of making a difference". He described an attitude that "it's more about doing what you believe in, doing what you've got a passion for, doing what you think is the right thing.

Passion seems to play an important role in the individual's decision to become an entrepreneur, as well as in their decision to continue along the entrepreneurial journey, as the external environment changes around them. Passion for the work plays a huge part in giving the entrepreneur the energy and desire to push through obstacles and overcome challenges throughout the entrepreneurial process (Cardon, Wincent, Singh, \& Drnovsek, 2009). All respondents described this love for what they do as a major part of their entrepreneurial motivation.

\section{Summary}

Chapter 4 presented the findings of the respondents narratives collected through semi-structured interviews, as well as the themes generated through interpretative phenomenological analysis. This was done in order to provide understanding of the respondents lived experience of entrepreneurial motivation and change. This study included interviews with seven entrepreneurs aged between 46 and 70 aimed at developing understanding of the relationship between entrepreneurial motivation and change. Through the interpretative phenomenological analysis of these interviews seven major themes relating to entrepreneurial motivation and change were discovered. The following chapter discusses these findings from the analysis in relation to the literature, the research questions and the conclusion of this thesis. 


\section{Chapter 5: Discussion and Conclusions}

\section{Introduction}

This chapter discusses the results of my study, interpreting the meaning of my studies results in relation to the research question. This is done first through a discussion of the themes and research question; comparing and contrasting descriptions of lived experience with the extant literature. This discussion engages in the exploration of what entrepreneurial motivation is and how it is affected by change. From this discussion an interpretation is provided of what these findings might mean to further understanding of the relationship between entrepreneurial motivation and change. Conclusions with regards to implications, limitations and future directions are then provided.

\section{Discussion of Themes}

This section presents a discussion of themes in relation to the extant literature. It discusses the importance of each theme, how it was described by respondents, and then links that description to the extant literature related to that theme. This provides the foundation from which a discussion of these findings in relation to the research question is provided in the following section. Once an understanding of each theme has been developed in terms of their importance to the research question, all seven are combined to provide my interpretation of how these themes interconnect to make up what entrepreneurial motivation is and how it is affected by change.

\section{External Environment}

The external environment can affect the entrepreneurial decision in two ways. Individuals become entrepreneurs either through necessity, or by opportunity as argued by Carsrud and Brannback (2011, P. 14) "the opportunistic entrepreneur is driven by the achievement of success through exploiting an opportunity for some form of gain... necessity entrepreneurs are more concerned with avoiding failure, which could mean starvation". My study contained individual's pulled in to entrepreneurship by the identification of an opportunity. This was described richly by respondents like Norman who reflected "I was talking to a friend, and we had quite a long liquid lunch, and we were talking about why we didn't seem to be rich, and we worked out that it was because we were working for somebody else... so this was on a Friday and literally on the Monday I went to a lawyer and said I would like to start a company". Others became entrepreneurs by necessity, such as being made redundant. Jack described this experience, expressing that "It was a good job... the company underwent restructuring... it was what do you do after 22 years 
when I was made redundant... it was a good job and I didn't see anything outside of that job, until it was forced upon me". These experiences are important in how they reflect on the effects of change in the individual's entrepreneurial journey.

All respondents experienced an external event that led them to engage in entrepreneurship, just as Norman and Jack did. The occurrence of external events sparking the entrepreneurial trajectory has been described in the literature. The external environment creates contexts in which the entrepreneur has the opportunity to decide whether to engage in entrepreneurship (Shapero \& Sokol, 1982). Whether they decide to exploit the opportunity introduced by the environment depends on their intentions, which are largely determined by that individual's attitude towards starting a business (Krueger, Reilly, \& Carsrud, 2000). This was reflected in all respondents who either by necessity or opportunity intended to engage in entrepreneurship.

The importance of this theme to the relationship between entrepreneurial motivation and change is that it disrupts the entrepreneur's current focus. These external events seem to be what sparks the internal drive of the entrepreneur (Grundsten, 2004). The entrepreneurial event is characterized by a large range of variables including social events, which can displace the individual, as happened to Jack and Parker. Once the individual is displaced, perceived feasibility and perceived desirability of entrepreneurship influence the individual's response, as noted by Shapero and Sokol (1982). In other words, the level of self-efficacy the individual feels towards entrepreneurship will determine how they respond to the opportunity (Atkinson, 1957). All respondents in my study decided that entrepreneurship was feasible and desirable, whether they were entrepreneurs by necessity or opportunity. Their motivation to engage in entrepreneurship was certainly influenced by a range of internal factors leading to a high degree of perceived desirability and feasibility with regards to entrepreneurship (Ajzen, 1991). The external environment brings about an entrepreneurial event, and sparks the entrepreneur's motivation, in this way the external environment is what creates the entrepreneurial trajectory.

\section{Upbringing}

All respondents described an upbringing which instilled in them important values, attitudes, and behaviours. It is their upbringing that gave them the internal characteristics necessary to be successful entrepreneurs. They described how watching their parents gave them a passion for business. This was clear for Patrick who described how "from a young age my dad would always be discussing business... I guess without business I don't know what I'd do with myself". Other 
respondents described how attitudes towards work were instilled, which was clear for Parker who stated "my family were hard workers... our family had an ethos of hard work and commitment". Respondents all had different upbringings, but it is clear that each of their upbringings was important in developing what would later become entrepreneurial motivation. This theme aids in the understanding of how entrepreneurial motivation is instilled in individuals through the norms, attitudes, and values learnt during childhood (Heckhausen \& Wrosch, 2010).

This theme is supported by findings in the literature. Our personality develops at a young age and is greatly influenced by our upbringing (Caspi \& Roberts, 2001). Values and motivations have been described as being closely related in that they are both linked to the notion of goals (Fayolle, Linan, \& Moriano, 2014). These findings are further grounded in respondents' descriptions with regards to the influence of upbringing on their values and motivations. Samuel described the link between values and motivations when describing how "I think [my drive] was mainly instilled by watching my parents... they were very hard workers... so I saw them toiling away when I was coming home from school". Norman discussed with me how important values were learnt during childhood even without a business background, reflecting that "it's interesting to look back because my mother had no education to speak of... my father had no high school education, so there was no family environment for business or entrepreneurship... I was encouraged to do the best that I could do in whatever discipline... my father was always encouraging me to be independent and self-sufficient". The development of personality during childhood instilled in these individuals important values that later become a part of their entrepreneurial motivation.

Upbringing influences entrepreneurial motivation and its relationship with change. The nature of this influence is that it determines the individual's attitudes towards change, work, and entrepreneurship. The literature also considers the relationship between upbringing and entrepreneurial motivation. The theory of planned behaviour has become an important theory in entrepreneurial motivation, as it proposes that "Intentions to perform behaviours can be accurately determined by an individual's attitudes, subjective norms, and perceived behavioural control" (Ajzen, 1991, P. 179). All traits that Ajzen lists seem to be instilled in the entrepreneur throughout their upbringing. The pervasiveness of attitudes and subjective norms remaining constant across their life is best illustrated through Parker who described that "my family was all hard workers... our family had an ethos of hard work and commitment... we didn't have all of the luxuries of life... I always felt it would take 
more than a regular salary to provide what I wanted for my family". When asked about his attitude towards work he described it as "making as much money as possible to provide a better life for my family". He learnt his family's ethos of hard work and commitment which he carried with him for the rest of his life.

Upbringing has a significant effect on values, attitudes, and beliefs more so than any other external influence (Kuczynski, Marshall, \& Schell, 1997). The socialization that occurs during upbringing may determine how individual's respond to the external environment as they go through changes in life. In that way an individual's upbringing may have a significant influence on their entrepreneurial motivation and the way in which they adapt to change. Upbringing plays an important part in influencing the development of characteristics that we would consider entrepreneurial. In that way it may determine whether individuals will have possessed the characteristics that make up entrepreneurial motivation, and whether they will successfully adapt to change.

\section{Drive}

Whether an individual possesses achievement motivation has been found to be correlated with both the choice to engage in entrepreneurial activity and entrepreneurial performance (Collins, Hanges, \& Locke, 2004). The results of this study support this finding across all respondents. Some individuals described how their desire to achieve things led them to engage in entrepreneurship. Norman described feeling "motivated and energetic... I've always felt motivated to do stuff and I can't imagine not being motivated... almost drawing from the changes happening to use as my energy". Others desire to achieve things led to a strong work ethic and increased entrepreneurial performance. This was experienced by Parker who described success being "because of my own effort and achievement and enthusiasm and commitment... I worked longer hours than most people, I went on courses, and I was committed to doing well". This internal drive to achieve things seems to be the basis from which entrepreneurial motivation comes forth.

Having a high need for achievement seems to make individuals more likely to engage in entrepreneurship, and then increase their performance once they do engage in it (Getley, 1979). A desire to achieve things may lead to a high level of adaptability to change in order to attain success. This has important implications for the objectives of this study. Having a need to achieve things affects the decision to engage in entrepreneurship as well as the decision to continue engaging in it. Motivation to engage in entrepreneurship across changing contexts is due to a persistent internal drive to achieve things. This was best described by Norman who 
expressed how "I still feel an inner drive, I'm not sure I'll ever feel content because for me it feels more like complacency... I hope the drive will always be there... external things change with time and the internal things are the engine room as it were, with the energy from that engine room being channelled in several directions".

The only individual who described this drive as not remaining constant over time was Patrick who when asked about his experience of drive described it as "diminishing and you know it is that dilemma a little bit of once you're financially comfortable, you know that is a motivating factor for sure, you don't quite have as much because you see that any additional money isn't going to make any difference to you at all". His experience is supported by Armstrong and Hird (2009) who found that entrepreneurs operating in the "early stages of venture creation and growth exhibit higher entrepreneurial drives than those operating in mature stages" (P. 419).

Having an internal drive to achieve things is an important aspect of entrepreneurial motivation, especially in relation to change. It is this internal drive the leads the entrepreneur to seek out situations in which they may achieve desired outcomes (Wood \& Michalisin, 2010). Once those desired outcomes have been achieved the entrepreneur moves on to another pursuit, still driven by a desire to achieve. Even as external drivers change across the entrepreneurial trajectory, this internal drive to achieve remains the same. This may help explain why some individuals are successful and others are not. Successful individuals are internally driven, and because of this persevere through challenges and tackle obstacles with energy and enthusiasm (Getley, 1979).

\section{Experience}

Previous experience has an important effect on the individual's self-belief. Experience and passion in the areas they have focused on throughout their corporate lives decrease the risk and ambiguity associated with entrepreneurship (Ajzen, 1991). This decreased risk and ambiguity leads to increased perceived feasibility of entrepreneurship. Because these individuals now believe that if they engage in entrepreneurship they can be successful, it contributes to their entrepreneurial motivation. A belief in their ability to successfully do something may lead to an increased motivation to do that thing.

Respondents described their relationship to risk and ambiguity as if it was almost irrelevant because they had a high degree of self-efficacy. When asked whether the move to entrepreneurship felt risky and ambiguous Jack reflected that "no, it really 
slotted in quite nicely actually... I was quite comfortable in what I was doing because I knew the job well". This respondents' experience is supported by the finding that tolerance for ambiguity is an important characteristic of the entrepreneur's motivation due to the ambiguous nature of entrepreneurship (Caliendo, Fossen, \& Kritikos, 2011). This may be true, but it seems that there is no need to tolerate ambiguity, because the decision is not perceived as ambiguous. This was exemplified by Samuel who described “well I haven't been very risk averse... I had 12 years apprenticeship of learning to be a good retailer; I felt I had enough experience under the belt to back myself". Respondents in my study did not perceive the decision to engage in entrepreneurship as risky because experience gave them a high sense of self-efficacy.

The role of experience with regards to self-efficacy has been discussed. McClelland claims that individuals high in NAch would have a moderate propensity for risk taking, because these factors both relate to the individuals self-efficacy or perceived behavioural control in relation to uncertainty (McClelland, 1961). This seems to be true in the experience of my respondents who all described feeling more in control of the outcome of their entrepreneurial journey due to their experience. This was expressed by Rick who stated that "I feel more prepared to do what I'm doing than someone who's in their 20s, just getting in to it... I feel that I've got a level of maturity with understanding how business works. The findings of this study support findings in the literature with regards to internal locus of control and selfefficacy accurately predicting an individual's entrepreneurial intentions (Chen, Greene, \& Crick, 1998).

The literature has discussed how the strength of an individual's self-efficacy determines how much effort will be expended, and how long it will be expended for in the face of adverse circumstance and changes in the external environment (Bandura, 1986). As these individual's experience growth in their ability to achieve success in their prospective areas of expertise, their belief in their ability to achieve further success increases (Segal, Borgia, \& Schoenfeld, 2005). As individual's belief in their ability increases their perception of the risks involved in entrepreneurship seems to decrease. This means that as time goes forward and the individual gains more experience in an area they will believe more in their ability to achieve in that area (Ajzen, 1991). Increased experience is one way in which change affects entrepreneurial motivation; as time goes forward the individual becomes more experienced and there is less risk and ambiguity associated with engaging in entrepreneurship. With increased self-efficacy decreasing perceived risk and 
ambiguity, feasibility of entrepreneurship is increased. As the individual becomes more experienced in an area they are more likely to perceive engaging in that area entrepreneurially as feasible and desirable.

\section{Adaptation}

This theme provides insight in understanding the relationship between entrepreneurial motivation and change. It describes how these individuals view their motivation or drive in relation to changing circumstances. Some respondents used the metaphor of sailing from one point to another. The theme itself essentially describes the entrepreneur's inner drive, or motivation, to get from point $\mathrm{A}$ to point B. There is an inner drive directed towards a particular goal. As things change and time goes on the entrepreneur must adapt to the changing environment in order to reach that goal. This inner drive is always there, and the point that it is directed towards changes across time. It seems as though the inner drive to achieve never subsides for the entrepreneur even as the external environment changes.

Some respondents used the metaphor of sailing to describe their experiences of the relationship between motivation and change. Norman described how it's "a bit like sailing where there's a goal or a point you want to reach, in the yacht, and you can't change the direction of the wind, but you can change the direction of the sails, so that's quite a good way to describe the entrepreneurial journey". All respondents described this feeling that their inner drive remained constant, whilst the external environment changed. Samuel stated that "I think things stay relatively the same... time goes by but the drive stays the same... you've got to change the way you think as the external things change... there is always external change that you've got to adapt to". Parker had a similar experience to Samuel, reflecting that "I don't think my motivation changed that much, I still do the business in order to improve mine and my family's lives... I know that in order to achieve what I want to achieve for my family I have to hit certain standards... it's the need to hit those standards that drives $\mathrm{me}^{\prime \prime}$.

The experience of my respondents can be related to findings in the literature. Our sense of self continues to change over our life time according to neurocognitive, cultural and social dynamics (Bee, Koh, \& Wang, 2012). However it would seem that the internal drive to achieve things that this self feels remains constant in my respondent's experience. In order to be successful organisations must adapt to external circumstances and learn from mistakes in order to continue forward in the direction of their goal. Just like organisations entrepreneurs must navigate through 
novel situations and ambiguous contexts over the course of their entrepreneurial career (Tolentino, Sedoglavich, Nhat Lu, Garcia, \& Restubog, 2014).

An individual's career adaptability has been found to help determine whether they will engage in entrepreneurship, depending on their level of self-efficacy with regards to doing so. The changing contexts of our lives do influence our personality (Heckhausen \& Wrosch, 2010). Whether changes occur depends greatly on an individual's interaction with the external environment and internal self (Caspi \& Roberts, 2001). It seems as though these influences do not include a change in the individual's desire to achieve things. Rather entrepreneurial individuals adapt as they must to the external environment, whilst continuously seeking to reach their goal.

\section{Risk}

When respondents were asked about their experience of risk and ambiguity in entrepreneurship they described not noticing much of a difference between their corporate and entrepreneurial roles. The reason for this was that their entrepreneurial roles were generally in the same area as their corporate role, which meant that they developed many of the capabilities required to do the entrepreneurial role in their corporate role. They described the idea that there is risk and ambiguity in both roles, just different kinds. There seemed to be an attitude that risk is pervasive across life. This attitude is important to the purpose of this study in that the attitude of universal acceptance towards risk provides the platform from which entrepreneurs may engage in what others may interpret as risky behaviour. In terms of entrepreneurial motivation it is a belief in the pervasiveness of risk that allows them to deal with the risk and ambiguity involved (Budner, 1962).

This was brought up multiple times in respondent's descriptions, with the most profound descriptions coming from Patrick and Rick. Patrick reflected that "certainly starting these businesses is risky and stressful...there is a lot of responsibility because you're feeding a number of mouths within the organisation... the nature of business is that it's risky and very competitive". He described his experience of stress and risk in both corporate and entrepreneurial roles "The gap between working in corporates and working for your self has really opened up... there are levels of stress in bureaucratic and entrepreneurial organisations, just different kinds". Rick reflected the same experience in his description, asserting that "Look you've never got control of everything, and there's ambiguity in the corporate world as well, you've just got to accept that [risk] and carry on". This is an important attitude to consider. If risk is pervasive and security is an illusion, then taking action 
in an entrepreneurial role may not be different to a corporate one. Having the right attitude towards risk is an essential aspect of entrepreneurial motivation.

A lot of the literature describes entrepreneurs as being far more tolerant of risks than managers. This ability to tolerate the risk involved with ambiguity is an important characteristic of the entrepreneur's motivation, due to the ambiguous nature of entrepreneurship (Caliendo, Fossen, \& Kritikos, 2011). However others have concluded that we do not yet know if the trait is an important differentiator between entrepreneurs and non-entrepreneurs (Shane, Locke, \& Collins, 2003). This is not necessarily true, and the literature seems to have a lot of conflicting evidence (Brockhaus R. , 1980). There must be other factors coming in to play that affect the individual's ability to tolerate risk, other than simply having a corporate role instead of an entrepreneurial one (Atkinson, 1957).

The main factor in decreasing perceived risk seems to be self-efficacy. Studies have found that risk taking propensity may be confounded with an individual's selfefficacy (Shane, Locke, \& Collins, 2003). Schumpeter didn't bring risk in to his discussion of the entrepreneur, because he believed both managers and entrepreneurs were subject to the risk of failure (Schumpeter, 1942). It seems that it is perceived self-efficacy that has an effect on risk tolerance, rather than entrepreneurs being more tolerant of risk than managers. My respondent's experience of the pervasiveness of risk mirrors these findings.

It has been conjectured that preference for moderate levels of risk is associated with the managerial demands of any job rather than just ownership (Brockhaus R. , 1980). If this were true it would mean that there is only a small difference between those in corporate managerial roles and those in entrepreneurial managerial roles. One prominent study by Robert H. Brockhaus (1980) describes how the failure of risk taking propensity to distinguish entrepreneurs from managers is very surprising. The reason for this is that the general theory establishes entrepreneurs as the greater risk takers. It seems that from the experience of my respondent's any individual who reaches a high level in business is a risk taker in some way or another. This would mean that in terms of entrepreneurial motivation the attitude you hold towards risk is a more important aspect to consider than the question of how an individual deals with the risks involved with entrepreneurship.

\section{Passion}

A love for one's work seems to be a powerful aspect of entrepreneurial motivation. Respondents described having a passion for what they did as the most significant 
aspect of their entrepreneurial motivation. What entrepreneurial motivation seems to be is an internal drive to achieve things, directed in a certain area of passion. Whatever area the individual loves bears the brunt of their entrepreneurial focus. Passion and drive seem to make up the majority of an individual's intrinsic motivation, which is directed towards whatever opportunity that individual has identified. It is clearly an important part of what entrepreneurial motivation is in my respondent's experience.

This theme came up in the narratives when respondents were discussing the role of passion in their entrepreneurial journey. Some respondents began work in an area and grew to love it. This was described by Parker who reflected on how "I became quite passionate about it, which was reflected in my work ethic... this passion led me to work longer hours than what was the usual... I loved it and so was driven to success in it". Others grew up in entrepreneurial or business environments which led to a love for business/entrepreneurship itself. Rick described this feeling of passion towards entrepreneurship, expressing that "I enjoyed my jobs but deep down the passion was there to do my own thing... I think I mentioned my family's background running their own businesses... and that was the way we operated".

Some scholars have linked entrepreneurial passion to the entrepreneur's ability to adapt and deal with environmental challenges (Cardon, Wincent, Singh, \& Drnovsek, 2009). This comes from the intense emotions of love, joy and enthusiasm that become an emotional resource. The love of doing the activities associated with their entrepreneurial role clearly gives these individuals the energy to drive forward. Respondent's described being energetic towards the activities involved in their career. This energy, coming from their entrepreneurial passion, enabled them to engage with much more tenacity than someone who is blasé about the activity. Passion rises and falls depending on whether the entrepreneur is engaged in the activities they feel passionate towards. This was shown in the narratives given by respondents when asked about whether passion plays a role in motivation. Norman described how his passion was for "the work I am doing at the moment rather than property and shopping malls... so yeah I have a passion for engineering... it's the fulfilment of doing the work and having the ability to do it well".

This finding is supported by the literature. Passion has been theorized to affect the level of self-efficacy individuals feel towards the activity that they love (Murnieks, Mosakowski, \& Cardon, 2014). This was reflected in the narratives where respondents expressed feeling a strong sense of self-efficacy in their area of expertise, possibly because it is what they loved. This idea of having passion for the 
work itself also came up in the narratives. Jack is one individual who describes that "It was passion... I liked my work all of the way through working at [corporate] to my own business in the forestry service... making money was on top of it but at the same time I just enjoyed doing the work... nowadays I don't need to do it but I like it... it's not work in the sense that most people think about work". It seems as though passion grows through experience in doing something, because as individuals have an increasing sense of self-efficacy towards an activity, they have an increasing feeling of love towards that activity.

In this sense the idea of work is different from the regular person. Most people see work as a negative thing that they must carry out in order to do things for leisure. But in all of my respondent's narratives they had continued working long after having enough money not to work anymore. Entrepreneurs are not motivated by the money entirely, there are internal motivations that remain pervasive across the entrepreneurial journey, and one of these motivations is a passion for the work that they do, which leads them to continue working long after they are financially successful.

\section{Discussion of Research Questions}

The objective of this study was to explore entrepreneurial motivation in relation to change. This objective was identified in the review Entrepreneurial Motivations: What do we still need to know? (Carsrud \& Brannback, 2011). In that review the authors propose a series of general motivation questions, including how do motivations and goals for entrepreneurs change over time?, which drove my interest in this project. It was an important question to ask because of implications for practitioners and scholars with regards to why and how entrepreneurs remain successful over time, and the mind-sets that determine whether an individual will be successful over time. This study asked what is entrepreneurial motivation and how is it affected by change. These questions will now be discussed in relation to the previous section discussion of the literature and respondents descriptions of lived experience.

\section{Entrepreneurial Motivation}

Entrepreneurial motivation is the drive to start and run a business successfully. Drive is not necessarily entrepreneurial in nature, but likely fits with McClelland's (1961) Need for Achievement. This drive becomes entrepreneurial when some external experience or event sparks the idea of starting a business. Some respondents experienced events such as recognising an opportunity that sparked their entrepreneurial motivation, whilst others became entrepreneurs by necessity when 
external events such as restructuring moved them from incredibly loyal company men to driven entrepreneurs.

This drive only became entrepreneurial after some external event. However it was clear that the drive itself came from the influence of these individuals upbringings. Every respondent described growing up with parents who instilled in them values, beliefs and attitudes that created this drive to achieve things. The influence of their upbringing in their eventual entrepreneurial motivation was a repeated theme in all entrepreneurs' narratives. Parker described learning the values of hard work and commitment "my family were hard workers... our family had an ethos of hard work and commitment". Norman learnt from his father independence and self-sufficiency "my father was always encouraging me to be independent and self-sufficient". Samuel described how his drive "was mainly instilled by watching my parents".

Norman described the drive to achieve as the engine room of entrepreneurial motivation. This description is significant in that it captures the essence of what entrepreneurial motivation is. His description reflected that "I still feel an inner drive... external things change with time, and the internal things are the engine room as it were, with the energy from that engine room being channelled in several directions". This description presents motivation as an internal energy that individual's channel in the form of taking action in order to achieve the ends they desire. This need to achieve things is clearly developed through family influence, even though each respondent had a unique socio-economic upbringing. Entrepreneurial motivation occurs when this need to achieve or inner drive is channelled in the direction of starting a business. There are many other factors surrounding the entrepreneurial process, but boiled down to its essence, whether through opportunity or necessity, entrepreneurial motivation is simply the energetic desire to start your own business and run it successfully.

This inner drive is confounded by the individual's passion and experience in the area of focus. Some individuals start multiple businesses across multiple economic sectors. But a major theme that came up in this study was that respondents were very experienced and very passionate about the areas in which they started their own businesses. This passion was in some individuals for business or entrepreneurship in general. Whilst for others it was for the job that they had done for many years. Passion gave them the necessary drive to do well once they moved in to entrepreneurship. It seems that passion for the work being done is an essential part of entrepreneurial motivation. Without passion the individual would not feel motivated towards making their business successful. Passion enables the 
entrepreneur to direct their focus energetically. This allows them to overcome the many challenges and road blocks often encountered during the entrepreneurial process. Where those without passion would break and give up, the entrepreneur pushes through.

One factor I found did not have much grounding in the narrative was a propensity for risk taking. This factor received much focus as an important part of entrepreneurial behaviour (Atkinson, 1957). However the results of this study support the finding that risk taking propensity may not be a distinguishable characteristic of entrepreneurs (Brockhaus R. , 1980). These results further support the suggestion that this finding may be due to measurement of the wrong concept, with risk taking propensity possibly being confounded with an individual's selfefficacy (Shane, Locke, \& Collins, 2003). The narratives brought about in this study found the recurring theme of respondents describing risk as not having much weight because they believed in their ability to overcome the challenges at hand. This belief in their ability to achieve outcomes was a result of being experienced and passionate in the areas they eventually became entrepreneurs.

\section{Entrepreneurial Motivation and Change}

Change affects an individual's entrepreneurial motivation before they start a business. Perceived feasibility of entrepreneurship is increased because as individuals become more experienced in an area they feel an increased sense of selfefficacy. The relationship between entrepreneurial motivation and change depends on the stage in the individual's life. If the individual has the inner drive that characterizes entrepreneurial motivation, along with a passion for the business they are involved in, the only thing required to push them in to starting their own business is self-efficacy and an external event providing an opportunity. In the preentrepreneurial phase of an individual's career change affects that individual's motivation to start a business through the generation of the self-efficacy required to take the risk. It also leads to the motivation to start a business through bringing about external events that spark the need to engage in entrepreneurship for necessity entrepreneurs or the opportunity to be exploited for opportunist entrepreneurs. But change cannot largely affect the internal drive to achieve things that many of these individuals feel.

Change is constant in life, the entrepreneur's internal drive may not change, but the external focus of that drive does. Entrepreneurial motivation is affected by change in terms of the entrepreneur developing their skills in the period before they engage in entrepreneurship. It is secondly influential in bringing about the external events that 
lead the entrepreneur to engage in entrepreneurship. However if we view 'motivation' as the internal desire to achieve things, change has no affect. Internally motivated individuals will always remain internally motivated no matter what happens externally. There is always another land to conquer and a new height to reach. But as we saw with the sailing metaphor change can bring about events that require the entrepreneur to adapt; external change can lead to a redirection of this internal motivation.

One entrepreneur described this with reference to Maslow's hierarchy of needs. Once the entrepreneur has made the money that once motivated they often change their focus to altruistic things such as doing good in the community. So change does not diminish the internal drive the individual has to achieve things in life; however it does change how this internal drive focuses itself in the external world. This thesis has focused on exploring the relationship between motivation and change. It did this through interpreting the lived experience of seven entrepreneurs. The exploratory nature of this study means that it provides just one possible interpretation of the themes present and should not be regarded as a universal description of the phenomena.

\section{Conclusion}

The conclusions drawn from this study are highly subjective. This is due to my role as interpreter. Bias is always present in qualitative research but as much as possible was removed. The aim of this study was to reach some level of understanding about what entrepreneurial motivation is and how it is affected by change. This understanding was developed through the interpretation of lived experience. The essence of the relationship between entrepreneurial motivation and change was drawn out through the combination of multiple lived experiences. My interpretation of what those lived experiences mean with regards to the research questions driving this study will now be provided. This interpretation draws on the previous sections linking of themes to the narratives of my respondents and the extant literature.

This section will offer my conclusions about the relationship between entrepreneurial motivation and change. It does not propose to have captured the universal nature of the phenomena. It does offer my interpretation of these phenomena based on the lived experience of the respondents involved in my study. This interpretation contributes to understanding the phenomena's universal nature with the hope of providing future directions for following researchers and practical implications for those interested in entrepreneurship and the study of entrepreneurship. 


\section{Interpretation of the relationship between entrepreneurial motivation and change}

Both themes and research questions were discussed in relation to the narratives and extant literature in the previous section. This discussion provided me with a final understanding of the meaning of these themes. All seven themes interconnect to provide understanding about entrepreneurial motivation and change. It is clear that the internal drive to achieve things provides the energy to consistently take action. Even if this drive to achieve things is not being expressed entrepreneurially to begin with, all respondents experienced that the external environment creates an entrepreneurial trajectory. This drive to achieve things and the role of passion in entrepreneurship seems to provide these individuals with the energy and enthusiasm to overcome challenges and obstacles across changing circumstances. All of which seem to be instilled within them in one form or another through the influence of upbringing in entrepreneurial motivation.

The risk involved in the decision to engage in entrepreneurship seems to be decreased for them, because experience builds self-efficacy which leads to decreased ambiguity and risk as they experience more success it becomes a self-fulfilling prophecy. This increased tolerance for risk seems to be confounded by an attitude that there is risk and ambiguity in both corporate and entrepreneurial roles which allows them to deal with ambiguity due to a belief that risk and ambiguity are pervasive in life. All of these themes come together to influence the entrepreneurs adaptation to changing circumstances as they are driven towards a certain point, as illustrated by sailing as a metaphor for entrepreneurial motivation.

\section{Practical Implications}

This section provides practical implications that entrepreneurs, teachers and potential entrepreneurs may draw from this study. The aim of this study was to develop a greater understanding of the relationship between entrepreneurial motivation and change. This understanding was developed through interpreting seven entrepreneurs lived experiences of that relationship. Understanding of the relationship between entrepreneurial motivation and change provides some practical implications.

From this thesis entrepreneurs may benefit from an increased understanding of changes effects on their motivation. As entrepreneurs go through their entrepreneurial journey their focuses may change. Once the individual has made enough money and established a successful business it may feel as though there is nothing left to do. However the nature of the drive to engage in entrepreneurial 
behaviour is a major asset to society. More entrepreneurs need to set their focuses on bigger goals instead of becoming complacent with mediocre achievement. Society requires individuals who are able to create prosperity. More entrepreneurs should continue to be high performers after achieving prosperity. Future study should aim to improve our understanding of what makes some individuals continue to achieve well after they may be considered successful.

Teachers may draw from this research ways of identifying potentially driven individuals. Even when students don't seem to be extremely intelligent or focused on studying, they may still have an inherent drive that has not been realized yet. If teachers are able to notice this drive in students it is clear from the extant literature that this drive can be taught and cultivated. Teachers should actively seek out students who are driven and aim to cultivate that drive. Business schools and public schools should continue to offer programs which help to improve their student's self-efficacy as this study has determined it to be a major factor in both entrepreneurial motivation and success in general.

Potential entrepreneurs should draw from this study lessons about their decision to engage in entrepreneurship. It is clear from this research that entrepreneurs usually engage in an area that they have focused on for many years. Potential entrepreneurs need to take in to account the importance of self-efficacy and passion in the area they choose to engage in. Whether they have developed the requisite capabilities in an area before venturing in to entrepreneurship will be a significant factor in their success. It seems that potential entrepreneurs should focus on discovering opportunities in an area that they have already put a large amount of focus in.

\section{Limitations of the Study}

The exploratory nature of this study means that it is not exhaustive and was conducted within the constraints of various limitations. These limitations have important implications for how this study should be perceived by scholars. Due to limitations of time and money the sample size of this thesis was very small even for a phenomenological study. Also due to its phenomenological methodology the findings of this study are highly subjective and generated through my interpretation of the lived experience of respondents through semi-structured interviews. My lack of experience in interviewing techniques may have prevented the level of richness in data from being optimal. The results are thus not as optimal as they could be and should be considered as one individual's interpretation of the phenomena rather than the universal nature of those phenomena. Some limitations can come up when using snowball sampling. Bias can occur when subjects refer the researcher to 
additional subjects who hold similar views to themselves. This may have occurred in my study due to additional respondents being friends of previous respondents. The small sample size, limited range and limited representativeness it provided may limit the generalizability of findings.

\section{Future Directions}

Through researching the behaviour, mind-sets, attitudes, values and experiences of entrepreneurs we can gain understanding about how these individuals think and perceive the world. The study of entrepreneurs and other successful individuals through an interpretative phenomenological approach allows us to better understand and differentiate between, those behaviours, mind-sets, attitudes, and values that lead to success and those that lead to failure. Future entrepreneurship research should engage in exploratory study of the entrepreneurial mind to improve understanding of what makes some individuals successful and others not. Further phenomenological study in to the entrepreneurial mind may look at the relationship between entrepreneurial mind-sets and failure. My study focused on internal characteristics that led to successful entrepreneurs. Future researchers should study what internal characteristics lead to unsuccessful entrepreneurs. Other important areas of study include why some entrepreneurs are satisfied with less success than others. 


\section{References}

Ajzen, I. (1991). The Theory of Planned Behavior . Organizational Behaviour and Human Decision Processes, 179-211.

Albrecht, T., \& Surprenant, C. (2006). Narrative. The Year's Work in Critical \& Cultural Theory, 89-116.

Alstete, J. W. (2008). Aspects of entrepreneurial success. Journal of Small Business and Enterprise Development, 584-594.

Ambrose, M. L., \& Kulik, C. T. (1999). Journal of Management. Old Friends, New Faces: Motivation Research in the 1990s, 231-292.

Armstrong, S. J., \& Hird, A. (2009). Cognitive Style and Entrepreneurial Drive of New and Mature Business Owner-Managers. Journal of Business and Psychology, 419-430.

Atkinson, J. W. (1957). Motivational Determinants of Risk-taking Behaviour. Psychological Review, 359-372.

Audretsch, D. (2012). Entrepreneurship research. Management Decision, 755-764.

Bagozzi, R. P., Dholakia, U. M., \& Basuroy, S. (2003). How Effortful Decisions Get Enacted: The Motivating Role of Decision Processes, Desires, and Anticipated Emotions. Journal of Behavioural Decision Making, 273-295.

Bandura, A. (1986). Social Foundations of Thought and Action: A Social Cognitive Theory. Englewood Cliffs, N.J: Prentice-Hall.

Baumol, W. J. (1968). Entrepreneurship in Economic Theory. The American Economic Review, 64-71.

Baumol, W., \& Strom, R. (2007). Entrepreneurship and Economic Growth. Strategic Entrepreneurship Journal, 233-237.

Bee, J., Koh, K., \& Wang, Q. (2012). Self-development. Wiley Interdisciplinary Reviews: Cognitive Science, 513-524.

Bird, B., \& Schjoedt, L. (2009). Entrepreneurial Behavior: Its Nature, Scope, Recent Research, and Agenda for Future Research. International Studies in Entrepreneurship, 327-358. 
Bowe, B., \& Sloan, A. (2014). Phenomenology and hermeneutic phenomenology. Quality \& Quantity, 1291-1303.

Brockhaus, R. (1980). Risk Taking Propensity of Entrepreneurs. Academy of Management Journal, 59-520.

Brockhaus, R. H. (1982). The psychology of the entrepreneur. In C. Kent, D. L. Sexton, \& K. H. Vesper, Encyclopaedia of Entrepreneurship (pp. 39-56). Englewood Cliffs, NJ: Prentice-Hall.

Budner, S. (1962). Intolerance for ambiguity as a personality variable. Journal of Personality, 29-50.

Burrell, G., \& Morgan, G. (2005). Sociological Paradigms and Organisational Analysis. Burlington: Ashgale Publishing Company.

Bygrave, W. D. (1989). The Entrepreneurship Paradigm: A Philosophical Look at Its Research Methodologies. Entrepreneurship: Theory \& Practice, 7-26.

Caliendo, M., Fossen, F., \& Kritikos, A. (2011). Personality Characteristics and the Decision to Become and Stay Self-Employed. Berlin: IZA Discussion Papers.

Cardon, M. S., Wincent, J., Singh, J., \& Drnovsek, M. (2009). The Nature and Experience of Entrepreneurial Passion. Academy of Management Review, 511532.

Carsrud, A., \& Brannback, M. (2011). Entrepreneurial Motivations: What Do We Still Need To Know? Journal of Small Business Management, 9-26.

Carsrud, A., Brannback, M., Elfving, J., \& Brandt, K. (2009). Motivations: The Entrepreneurial Mind and Behavior. International Studies in Entrepreneurship, 141-165.

Caspi, A., \& Roberts, B. W. (2001). Personality Development across the Life Course: The Argument for Change and Continuity. Psychological Inquiry, 49-66.

Cavana, R. Y., Delahaye, B. L., \& Sekaran, U. (2001). Applied Business Research: Qualitative and Quantitative Methods. Milton, Qld: John Wiley \& Sons.

Chell, E. (2007). Social Enterprise and Entrepreneurship: Towards a Convergent Theory of the Entrepreneurial Process. International Small Business Journal, 526. 
Chen, C. C., Greene, P. G., \& Crick, A. (1998). Does entrepreneurial self-efficacy distinguish entrepreneurs from managers? Journal of Business Venturing, 295316.

Collins, C., Hanges, P., \& Locke, E. (2004, 31 07). The Relationship of Achievement Motivation to Entrepreneurial Behaviour: A Meta-Analysis [Electronic Version]. Retrieved from Cornell University, ILR School: http://digitalcommons.ilr.cornell.edu/cgi/viewcontent.cgi?article=1841\&conte $\mathrm{xt}=$ articles

Cooper, J., \& Hartnett, T. (2010). Issues is research ethics: privacy and confidentiality. Research Practitioner, 94+.

Creswell, J. W. (2012). Qualitative inquiry and research design: Choosing among five approaches. Los Angeles: SAGE Publications

Davidson, P. (1996). Reality and Economic Theory. Journal of Post Keynesian Economics, 479-508.

Deci, E. (1975). Intrinsic Motivation (Perspectives in Social Psychology) . New York: Plenum Press.

Delgado-Garcia, J. B., Rodríguez-Escudero, A. I., \& Martín-Cruz, N. (2012). Influence of Affective Traits on Entrepreneur's Goals and Satisfaction. Journal of Small Business Management, 408-428.

Drucker, P. F. (1985). Innovation and Entrepreneurship. New York: HarperCollins.

Engle, R. L., Dimitriadi, N. D., Gavidia, J. V., Schlaegel, C., Delanoe, S., Alvarado, I., . . . Wolff, B. (2010). Entrepreneurial intent: A twelve-country evaluation of Ajzen's model of planned behavior. International Journal of Entrepreneurial Behaviour \& Research, 35-57.

Farmer, S., Yao, X., \& Kung-Mcintyre, K. (2011). The Behavioral Impact of Entrepreneur Identity Aspiration and Prior Entrepreneurial Experience. Entrepreneurship Theory and Practice, 245-273.

Fayolle, A., Linan, F., \& Moriano, J. A. (2014). Beyond entrepreneurial intentions: values and motivations in entrepreneurship. International Entrepreneurship and Management Journal , 679-689. 
Florin, J., Karri, R., \& Rossiter, N. (2007). Fostering Entrepreneurial Drive In Business Education: An Attitudinal Approach. Journal of Management Education, 17-42.

Frese, M., \& Gielnik, M. M. (2014). The Psychology of Entrepreneurship. The Annual Review of Organizational Psychology, 413-438.

Frese, M., \& Rauch, A. (2000). Psychological approaches to entrepreneurial success: A general model and an overview of findings. International Review of Industrial and Organizational Psychology, 102-142.

Gadamer, H.-G. (1975). Hermeneutics and Social Science. Philosophy \& Social Criticism, 307-316.

Garg, A., Matshediso, I., \& Garg, D. (2011). An individuals motivation to become entrepreneur: evidences from a mineral based economy. Internation Journal of Entrepreneurship and Small Business, 109-122.

Gartner, W. B. (1989). 'Who Is An Entrepreneur?' Is The Wrong Question. Entrepreneurship theory and practice, 47-67.

Getley, R. (1979). Entrepreneurial Drive. Industrial and Commercial Training, 19-23.

Gibson, C. (1998). Semi-Structured and Unstructured Interviewing: A comparison methodologies in research with patients following discharge from an acute psychiatric hospital. Journal of Psychiatric and Mental Health Nursing, 469-477.

Grundsten, H. (2004). Entrepreneurial Intentions and the Entrepreneurial Environment: A Study of Technology-Based New Venture Creation. Champaign: University of Illinois at Urbana-Champaign's Academy for Entrepreneurial Leadership Historical Research Reference in Entrepreneurship.

Guba, E. G., \& Lincoln, Y. S. (1994). Competing Paradigms in Qualitative Research. In N. K. Denzin, \& Y. S. Lincoln, Handbook of qualitative research (pp. 107-117). Thousand Oaks, CA: Sage.

Harrell, T., \& Alpert, B. (1979). The Need for Autonomy Among Managers. The Academy of Management Review, 259-267.

Heckhausen, J., \& Wrosch, C. (2010). A Motivational Theory of Life-Span Development. Psychological Review, 32-60. 
Hoang, H., \& Gimeno, J. (2010). Becoming a founder: How founder role identity affects entrepreneurial transitions and persistence in founding. Journal of Business Venturing, 41-53.

Hollway, W., \& Jefferson, T. (2000). Doing Qualitative Research Differently . London, United Kingdom: SAGE Publications.

Jayawarna, D., Rouse, J., \& Kitching, J. (2011). Entrepreneur motivations and life course. International Small Business Journal, 34-56.

Kam Wong, P., Yuen, P. H., \& Autio, E. (2005). Entrepreneurship, Innovation and Economic Growth: Evidence from GEM data. Small Business Economics, 335350 .

Krueger, N. F., Reilly, M. D., \& Carsrud, A. L. (2000). Competing models of entrepreneurial intentions. Journal of Business Venturing, 411-432.

Krueger, N., \& A., C. (1993). Entrepreneurial intentions: Applying the Theory of Planned Behaviour. Entrepreneurship \& Regional Development: An International Journal, 315-330.

Kuczynski, L., Marshall, S., \& Schell, K. (1997). Parenting and Childrens Internalization of Values: A Handbook of Contemporary Theory. New York: Wiley.

Laverty, S. M. (2003). Hermeneutic Phenomenology and Phenomenology: A Comparison of Historical and Methodological Considerations. International Journal of Qualitative Methods, 21-35.

Lerner, R. M. (1990). Weaving Development into the Fabric of Personality and Social Psychology: On the. Psychological Enquiry, 92-96.

McAdams, D. P., \& Olson, B. D. (2010). Personality Development: Continuity and Change Over the Life Course. Annual Review of Psychology, 517-542.

McClelland, D. C. (1961). The Achieving Society. Champaign, IL: University of Illinois at Urbana-Champaign's Academy for Entrepreneurial Leadership Historical Research Reference in Entrepreneurship.

Michael, S. C. (2007). Entrepreneurship, Growth, and Adam Smith. Strategic Entrepreneurship Journal, 287-289.

Moustakas, C. (1994). Phenomenological research methods. Thousand Oaks, CA: SAGE Publications. 
Murnieks, C., Mosakowski, E., \& Cardon, M. (2014). Pathways of Passion: Identity Centrality, Passion, and Behavior Among Entrepreneurs. Journal of Management, 1583-1606.

Naffziger, D. W., Hornsby, J. S., \& Kuratko, D. F. (1994). A proposed research model of entrepreneurial motivation. Entrepreneurship Theory and Practice, 29-42.

Naktiyok, A., Nur Karabey, C., \& Caglar Gulluce, A. (2010). Entrepreneurial selfefficacy and entrepreneurial intention: the Turkish case. International Entrepreneurship and Management Journal, 419-435.

Nielsen, S. L., \& Lassen, A. H. (2012). Identity in entrepreneurship effectuation theory:. International Entrepreneurship and Management Journal, 373-389.

Nurmi, J.-E. (1992). Age Differences in Adult Life Goals, Concerns, and Their Temporal Extension: A Life Course Approach to Future-oriented Motivation. International Journal of Behavioural Development, 487-508.

Osborne, J. W. (1994). Some similarities and differences among phenomenological and other methods of psychological qualitative research. Canadian Psychology, 167-189.

Owoseni, O. O. (2014). The Influence of Some Personality Factors on Entrepreneurial Intentions. International Journal of Business and Social Science, 278-284.

Pierre-Andre, J. (1989). The Entrepreneur and Economic Theory. International Small Business Journal, 29-38.

Pietkiewicz, I., \& Smith, J. A. (2014). A practical guide to using Interpretative Phenomenological Analysis in qualitative research psychology. Psychological Journal, 7-14.

Pinillos, M.-J. (2011). the Intellectual Structure of Entrepreneurial Motivation: A Citation/Cocitation Analysis. China-USA Business Review, 285-297.

Polkinghorne, D. E. (1988). Narrative Knowing and the Human Sciences. Albany, NY: State University of New York Press.

Rauch, A., \& Frese, M. (2000). Psychological approaches to entrepreneurial success: A general model and an . International Review of Industrial and Organizational Psychology, 101-142. 
Rotter, J. B. (1966). Generalized Expectancies for Internal VS External Control of Reinforcement. Psychological Monographs: General and Applied, 1-28.

Ryan, R. M., \& Deci, E. L. (2000). Intrinsic and Extrinsic Motivations: Classic Definitions and New Directions. Contemporary Educational Psychology, 54-67.

Ryan, R. M., \& Deci, E. L. (2000). Self-Determination Theory and the Facilitaion of Intrinsic Motivation, Social Development, and Well-Being. American Psychologist, 68-78.

Sanchez, J., Carbello, T., \& Gutierrez, A. (2011). The entrepreneur from a cognitive approach. psicothema, 433-438.

Sansone, C., \& Harackiewicz, J. (2000). Intrinsic and Extrinsic Motivation: The Search for Optimal Motivation and Performance. Waltham, Massachusetts: Academic Press.

Schultheiss, O., Strasser, A., Rosch, A., Kordik, A., \& Graham, S. (2012). Motivation. Encyclopedia of Human Behaviour, 650-656.

Schumpeter, J. (1942). The Process of Creative Destruction. In J. Schumpeter, Capitalism, Socialism and Democracy (p. 81). New York: Routledge.

Schwandt, T. A. (2007). The SAGE Dictionary of Qualitative Inquiry. Thousand Oaks, CA: SAGE Publications.

Segal, G., Borgia, D., \& Schoenfeld, J. (2005). The motivation to become an entrepreneur. International Journal of Entrepreneurial Behaviour \& Research, 4257.

Shane, S., \& Venkataraman, S. (2000). The Promise of Enterpreneurship as a Field of Research. The Academy of Management Review, 217-226.

Shane, S., Locke, E. A., \& Collins, C. J. (2003). Entrepreneurial Motivation. Human Resource Management Review, 257-279.

Shapero, A., \& Sokol, L. (1982). The Social Dimensions of Entrepreneurship. In Encyclopedia of Entrepreneurship (pp. 72-90).

Smith, J. A., Flowers, P., \& Larkin, M. (2009). Interpretative phenomenological analysis: theory, method and research. Los Angeles: Sage.

Solesvik, M. V. (2013). Entrepreneurial motivations and intentions: investigating the role of education major. Education + Training, 253-271. 
Sullivan, S. E., Forret, M. L., Mainiero, L. A., \& Terjesen, S. (2007). What Motivates Entrepreneurs? An Exploratory Study of the Kaleidoscope Career Model and Entrepreneurship. Journal of Applied Management and Entrepreneurship, 4-19.

Taormina, R. J., \& Kin-Mei Lao, S. (2007). Measuring Chinese entrepreneurial motivation: Personality and environmental influences. International Journal of Entrepreneurial Behaviour E Research, 200-221.

Tetlock, P. E., \& Levi, A. (1982). Attribution bias: On the inconclusiveness of the cognition-motivation debate. Journal of Experimental Social Psychology, 68-88.

Thompson, J. L. (2004). The facets of the entrepreneur: identifying entrepreneurial potential. Management Decision, 243-258.

Tolentino, L. R., Sedoglavich, V., Nhat Lu, V., Garcia, P., \& Restubog, S. (2014). The role of career adaptability in predicting entrepreneurial intentions: A moderated mediation model. Journal of Vocational Behavior, 403-412.

Vij, S., \& Sharma, P. (2013). Does Entrepreneurial Education Enhance the Entrepreneurial Drive of Business Students? IUP Journal of Entrepreneurship Development, 65-82.

Vijaya, V., \& Kamalanabhan, T. J. (1998). A Scale to Assess Entrepreneurial Motivation. The Journal of Entrepreneurship, 183-198.

White, R. E., Thornhill, S., \& Hampson, E. (2006). Entrepreneurs and evolutionary biology: The relationship. Organizational Behavior and Human Decision Processes, 21-34.

Wood, M. S., \& Michalisin, M. D. (2010). Entrepreneurial Drive in the Top Management Team: Effects on Strategic Choice and Firm Performance. Journal of Leadership \& Organizational Studies, 222-239.

Wurthmann, K. (2014). Business students' attitudes toward innovation and intentions to start their own business. International Entrepreneurship and Management Journal, 691-711.

Zeffane, R. (2013). Need for Achievement, Personality and Entrepreneurial Potential: A Study of Young Adults in the United Arab Emirates. Journal of Enterprising Culture, 75-105. 


\section{Appendices}

\section{Appendix A \\ CONSENT TO PARTICIPATE IN RESEARCH}

\section{An Exploratory Study in to Entrepreneurial Motivation in Changing Contexts}

I have been given and have understood an explanation of this research project. I have had an opportunity to ask questions and have them answered to my satisfaction. I understand that I may withdraw myself (or any information I have provided) from this project before December 142014 without having to give reasons.

I understand that any information I provide will be kept confidential to the researcher, the supervisor and the person who transcribes the tape recordings of our interview. I understand the published results will not use my name, and that no opinions will be attributed to me in any way that will identify me. I understand that the tape recording of interviews will be wiped at the end of the project unless I indicate that I would like them returned to me. I understand that I will have an opportunity to check the transcripts of the interview before publication. I understand that the data I provide will not be used for any other purpose or released to others without my written consent.

Signed:

Name of participant:

Date: 


\section{Appendix B \\ UNSTRUCTURED INTERVIEW TOPIC GUIDE}

\section{An Exploratory Study in to Entrepreneurial Motivation in Changing Contexts}

My aim is to engage the respondent in an in-depth, interactive dialogue regarding their motivation during the changing contexts of their entrepreneurial journey. This guide will enable me to focus on the theme I have chosen to examine in these interviews. Content and order of questions may change from interview to interview, and I will use a range of non-scheduled prompts and probes to help the respondent generate a narrative of their entrepreneurial journey.

\section{List of possible topics and questions to engage respondent on:}

- So to start off could you please give me a general overview of your career from the first job you had to your latest venture?

- What have you experienced in terms of motivation in entrepreneurship?

- And what influences your experience of entrepreneurial motivation?

- Attitude - What has your attitude been towards work?

- Internal and External Motivation - Do you think it is the internal or external things that motivate you most?

- Need For Achievement - Have you always had a need to achieve things in life?

- Risk Taking Propensity - What are your thoughts on the role of risk in being an entrepreneur

- Internal Locus of control - Have you always believed in your capabilities to achieve things or has it grown across your life

- Self-Efficacy

- Tolerance for ambiguity - What do you think about ambiguity and uncertainty?

- Autonomy

- TPB - Did you always have the intention to become an entrepreneur?

- Drive - What would you describe your drive in life to be

- Passion - Does passion for your work play a role in your motivation? How?

- Independence - have you always felt a need to be independent?

- Change - What has the role of change played in your entrepreneurial journey been

- Mental Models - have you had to change the way you think about things or has your overall mind-set been consistent? 
- Principles - Do you think there are universal principles to success in any area? And if so have you learnt them across your journey or known them from the start?

(Interview guide may be modified during the interview or from one interview to the next and I will follow the informant's lead asking for explanations and examples of their accounts)

\section{Schedule of interview process}

- Opening comfort talk

- Bring conversation towards the topic of motivation and entrepreneurialism

- Probe for further information whilst keeping the dialogue on track through prompts

- Push towards deeper topic of entrepreneurial journey

- Probe further towards a narrative of motivation and entrepreneurship

- Remain open to conversation until respondent is comfortable ending

- Closing comfort talk and briefing of what was said 


\section{Appendix C}

\section{Master table of Themes}

1. External environment creates entrepreneurial Trajectory
a. Pushed in to Entrepreneurship (Jack, 1)
b. Being made redundant and wanting money $(J a c k, 9)$
c. Restructuring of company (Parker, 1)
d. Epiphany to Start working hard (Wallace, 3)
e. Mission control center (Norman, 11)
f. Family

2. Influence of Upbringing on Entrepreneurial Motivation
a. Family influence on values (Norman, 2)
b. Family influence on values (Parker, 4)
c. Family influence on values (Rick, 1)
d. Family influence on values (Samuel, 2\&3)

3. Internal drive to achieve things is constant
a. Focused on achieving results (Jack, 3)
b. Mindset stayed consistent over time (Jack, 10)
c. Self-actualization, change in drives (Norman, 16\&22\&25)
d. Nach (Parker, 2\&8\&20)
e. Internal drive remains the same whilst external motivators change (Rick, 14)

f. External things change but internal drive is always there (Samuel, 14)

4. Experience builds Self-efficacy which leads to decreased ambiguity and risk
a. Belief in capabilities (Patrick, 21)
b. Resources and capabilities contribute to self-efficacy (Rick, 11)
c. Increased belief in capabilities (Wallace, 13)
d. Risk doesn't matter when you believe in your capabilities (Norman, 10)
e. Experience gave self-efficacy (Samuel, 9)
f. Experience at company made me feel just as capable (Jack, 5)

5. Sailing as a metaphor for the relationship between entrepreneurial motivation and change
a. External things change, but internal things remain the same, yacht analogy (Wallace, 23)
b. yacht analogy for change (Norman, 21)

6. There is risk and ambiguity involved in both corporate and entrepreneurial roles
a. Ambiguity is pervasive (Rick, 15) 
b. There is stress in both entrepreneurial and corporate roles (Patrick, 8)

d. Low difference in responsibility (Parker, 15)

e. Felt the same moving from corporate to entrepreneurial role (Jack, 6)

7. Providing for family as an entrepreneurial motivation

a. Doing well for family as a major motivator (Patrick, 14)

b. Family responsibilities (Rick, 1)

c. Trade-off with family and friends (Norman, 23)

d. Wanted to do well for family (Samuel, 10)

e. Family oriented (Jack, 4)

f. Provide for family (Parker, 4)

8. The role of passion in entrepreneurship

a. Passion for work keeps him going (Jack, 14)

b. Passion led to strong work ethic (Parker, 18)

c. Passion creates energy (Rick, 21)

d. Passion for business (Patrick, 23) 
